\title{
Fully-Coupled Fluid-Structure Interaction Simulations of a Supersonic Parachute
}

Jonathan Boustani ${ }^{*+}$, Michael F. Barad ${ }^{+}$, Cetin C. Kiris ${ }^{+}$, Christoph Brehm*

Program Director, Dr. Suzanne Smith

Grant Number, RIDG-17-005

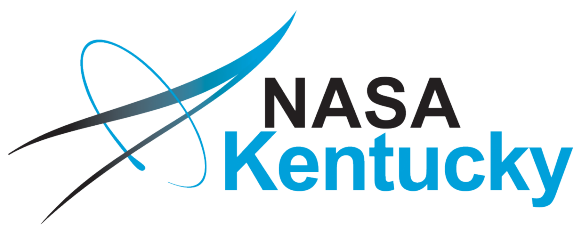

HPC Resources Provided by

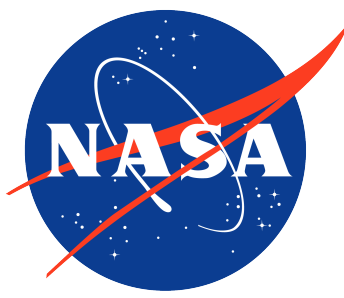

*Department of Mechanical Engineering, University of Kentucky, Lexington, KY, 40506, USA

${ }^{+}$Computational Aerosciences Branch, NASA Ames, Moffet Field, CA, 94035, USA 


\section{Outline}

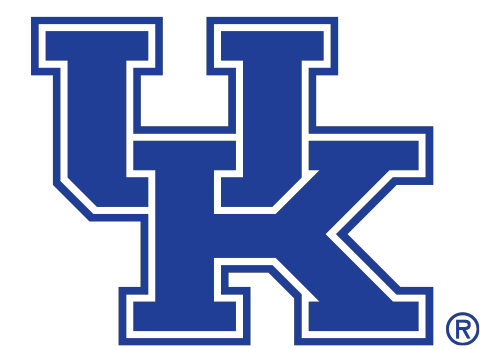

$\square$ Motivation/Introduction

o Mars, EDL system qualification, Simulation Capabilities

$\square$ FSI Method

○ Governing equations

- Immersed Boundary Method for the Compressible Navier-Stokes Equations (CFD)

- Geometrically Nonlinear Computational Structural Dynamics Solver (CSD)

- Coupling procedure

$\square$ Extended Validation for Fluid-Structure Interaction Problems

$\square$ Methods for Large-scale, Parallel CFD-CSD Coupling

o Disparate domain decomposition

$\square$ Supersonic Parachute Inflation

$\square$ Summary and Outlook 


\section{Outline}

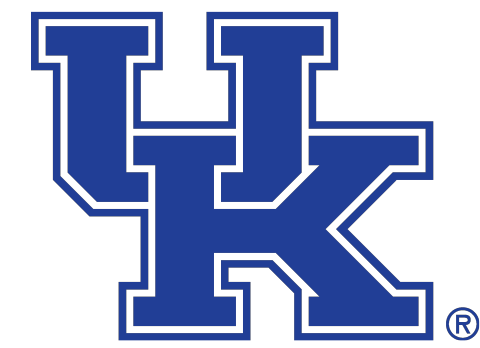

\section{Motivation/Introduction}

o Mars, EDL system qualification, Simulation Capabilities

$\square$ FSI Method

○ Governing equations

- Immersed Boundary Method for the Compressible Navier-Stokes Equations (CFD)

○ Geometrically Nonlinear Computational Structural Dynamics Solver (CSD)

○ Coupling procedure

$\square$ Extended Validation for Fluid-Structure Interaction Problems

$\square$ Methods for Large-scale, Parallel CFD-CSD Coupling

o Disparate domain decomposition

$\square$ Supersonic Parachute Inflation

$\square$ Summary and Outlook 


\section{Motivation}

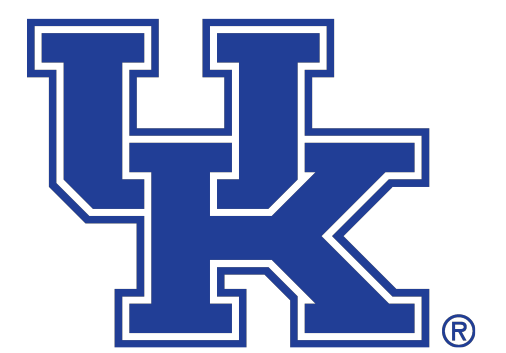

$\square$ MSL EDL system was requalified

o Payload weight, canopy size, and landing altitude exceeded those established by heritage Viking mission

(Sengupta et al. AIAA 2007,2009, Way et al. IEEE 2006)

$\square$ NASA's mission to Mars will eventually require EDL requalification

o For hardware and humans required for sustained settlements, more demanding landing objectives

$\square$ LDSD project

o Supersonic ringsail parachute

o Low-Density Supersonic Decelerator

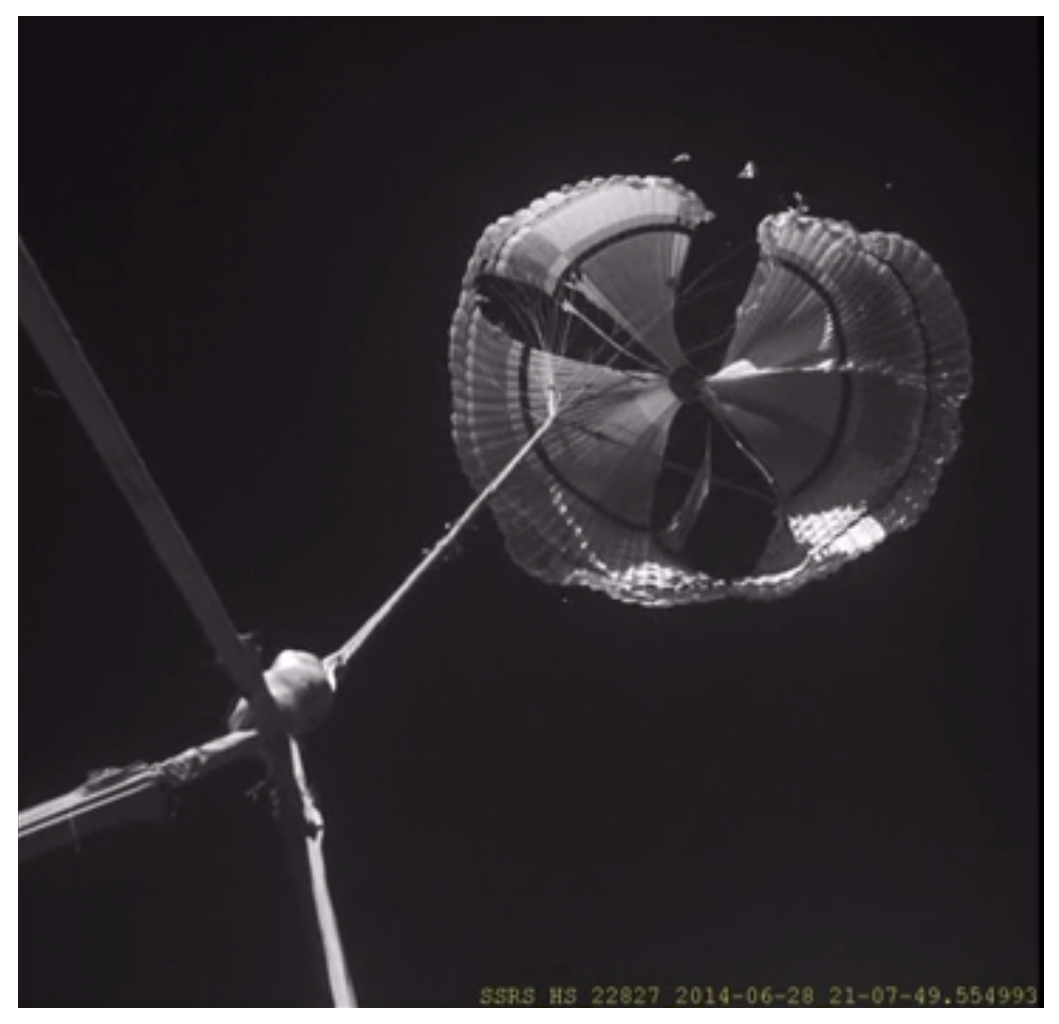

(NASA) 


\section{Introduction}

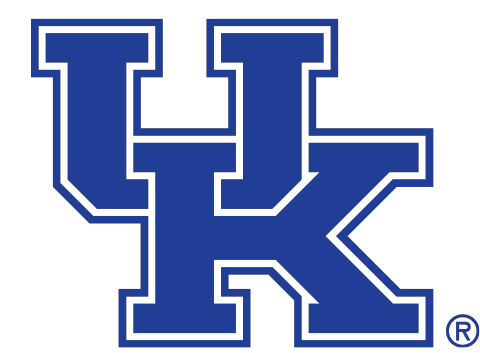

$\square$ Previously introduced and validated a method for simulating the large, geometrically nonlinear deformations of very thin shell structures (Boustani et al. SciTech 2019)

$\square$ This work is an extension of these capabilities to solving large-scale FSI problems in high-speed flows within a parallel computing environment

$\square$ End goal is to simulate supersonic parachute deployment
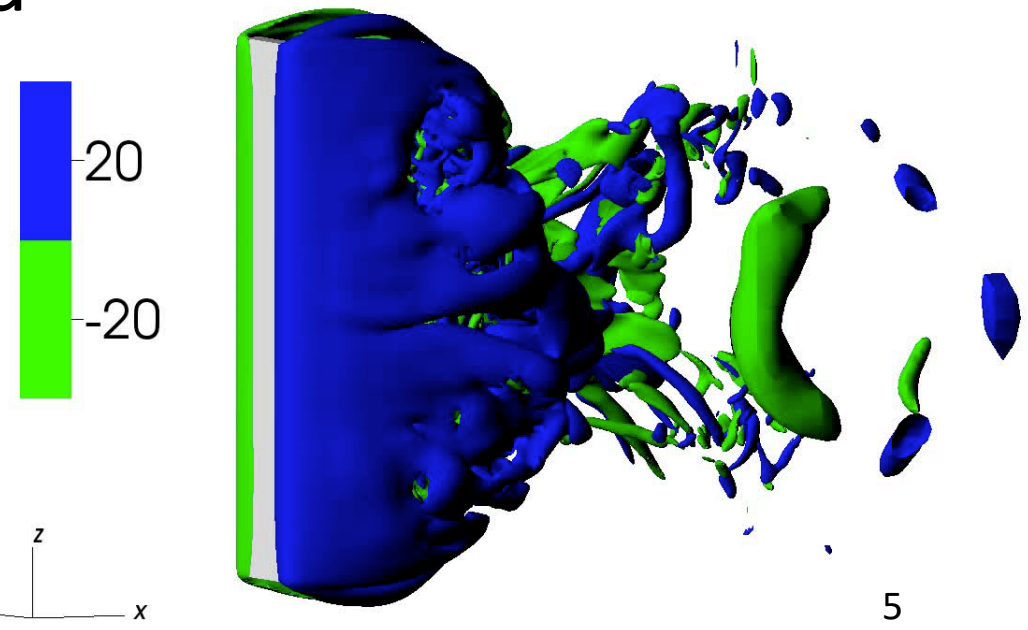


\section{Outline}

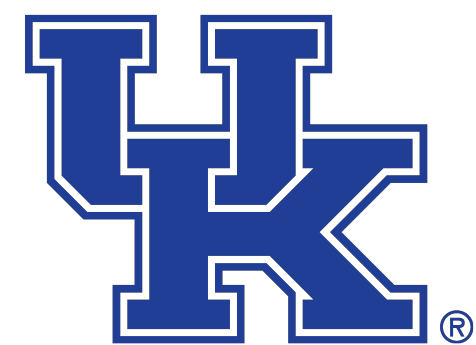

$\square$ Motivation/Introduction

- Mars, EDL system qualification, Simulation Capabilities

\section{$\square$ FSI Method}

○ Governing equations

- Immersed Boundary Method for the Compressible Navier-Stokes Equations (CFD)

- Geometrically Nonlinear Computational Structural Dynamics Solver (CSD)

- Coupling procedure

$\square$ Extended Validation for Fluid-Structure Interaction Problems

$\square$ Methods for Large-scale, Parallel CFD-CSD Coupling

o Disparate domain decomposition

$\square$ Supersonic Parachute Inflation

$\square$ Summary and Outlook 


\section{Governing Equations}

$\square$ The fluid regime considers the compressible Navier-Stokes equations, shown here in conservative form

$$
\begin{aligned}
& \frac{\partial \mathbf{W}}{\partial t}+\frac{\partial \mathbf{E}}{\partial x}+\frac{\partial \mathbf{F}}{\partial y}+\frac{\partial \mathbf{G}}{\partial z}=0 \\
& \mathbf{W}=\left[\rho, \rho u, \rho v, \rho w, \rho e_{t}\right]^{T}
\end{aligned}
$$

$\square$ The structural regime considers the Total Lagrangian equations of motion

$$
\int_{{ }_{0} V}{ }_{0} \boldsymbol{S}_{i j} \delta_{0} \boldsymbol{\epsilon}_{i j} d^{0} V+\int_{{ }_{0} V}{ }_{0}^{t} \boldsymbol{S}_{i j} \delta_{0} \boldsymbol{\eta}_{i j} d^{0} V={ }^{t+\Delta t} \boldsymbol{\mathcal { R }}-\int_{{ }^{0} V}{ }_{0}^{t} \boldsymbol{S}_{i j} \delta_{0} \boldsymbol{e}_{i j} d^{0} V
$$

$\square$ Partitioned solution involves solving strong and weak solutions together 


\section{Coupling Conditions}

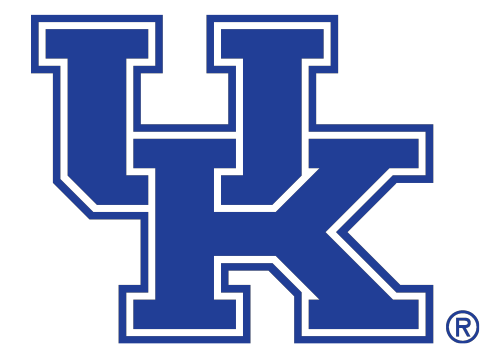

$\square$ The coupling conditions between the two regimes enforce the continuity of loads across the shared boundary

$$
\mathbf{t}_{\text {structure }}\left(\overline{\mathbf{x}}_{b}(t), t\right)=\mathbf{t}_{\text {fluid }}\left(\overline{\mathbf{x}}_{b}(t), t\right)
$$

where the fluid traction vector considers pressure and viscous stresses

$\square$ The continuity of the position and velocity of the shared boundary itself is also enforced

$$
\begin{aligned}
& \overline{\mathbf{x}}_{b}(t)=\mathbf{x}_{\text {fluid }}(t)=\mathbf{x}_{\text {structure }}(t), \text { and } \\
& \dot{\mathbf{x}}_{b}(t)=\dot{\mathbf{x}}_{\text {fluid }}(t)=\dot{\mathbf{x}}_{\text {structure }}(t) \quad \forall t \geq 0
\end{aligned}
$$




\section{FSI Method}

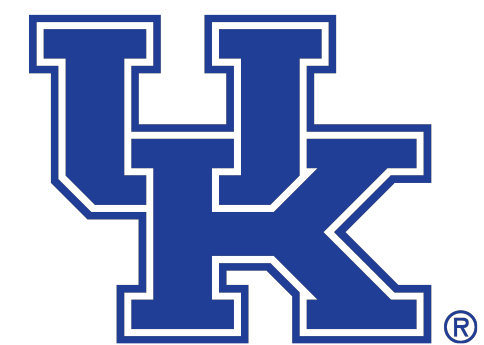

$\square$ The method used in this work couples together

I. A structured Cartesian, higher-order, sharp immersed boundary method for the compressible Navier-Stokes equations

Brehm, C., Fasel, H., JCP 2013

Brehm, C., Hader, C., Fasel, H., JCP 2015

Brehm, C., Barad, M. F., Kiris, C. C., JCP 2018

II. A geometrically nonlinear structural finite element solver employing shell elements that utilize the Mixed Interpolation of Tensorial Components

Boustani et al., AIAA SciTech 2019
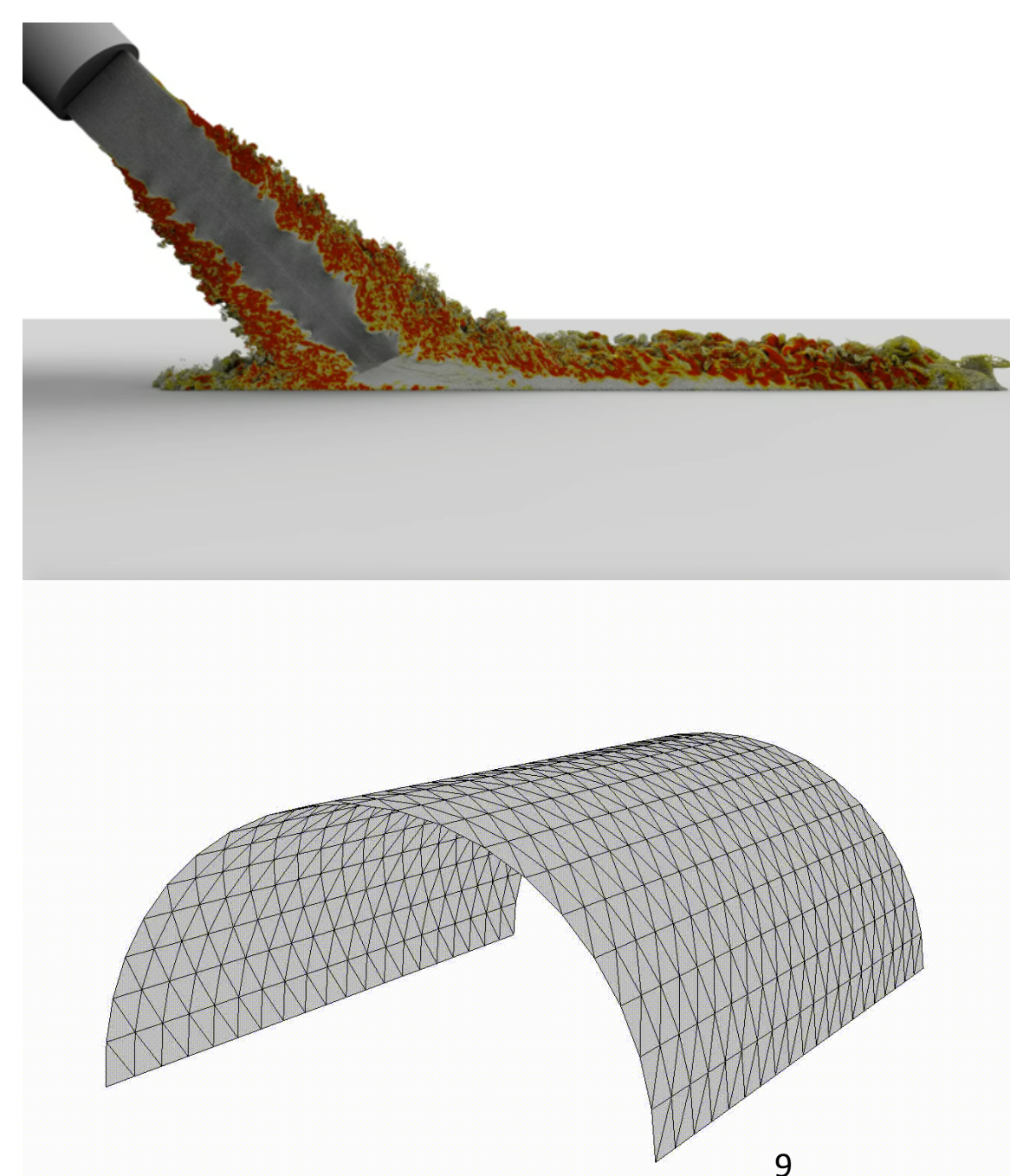


\section{Higher-Order IBM}

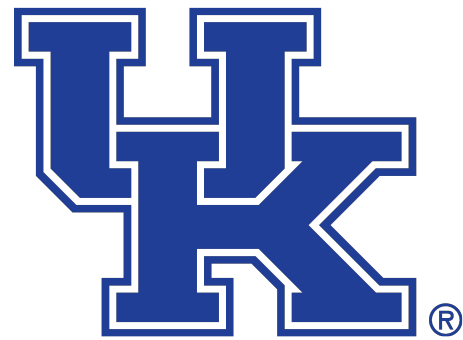

$\square$ FD stencils are locally optimized considering the local flow conditions and boundary distance

o Improved stability

$\square$ Compressible Navier-Stokes are solved with the $4^{\text {th }}$ - order time explicit Runge-Kutta scheme

$\square$ WENO5 is used for the convective terms to deal with flow

(a)

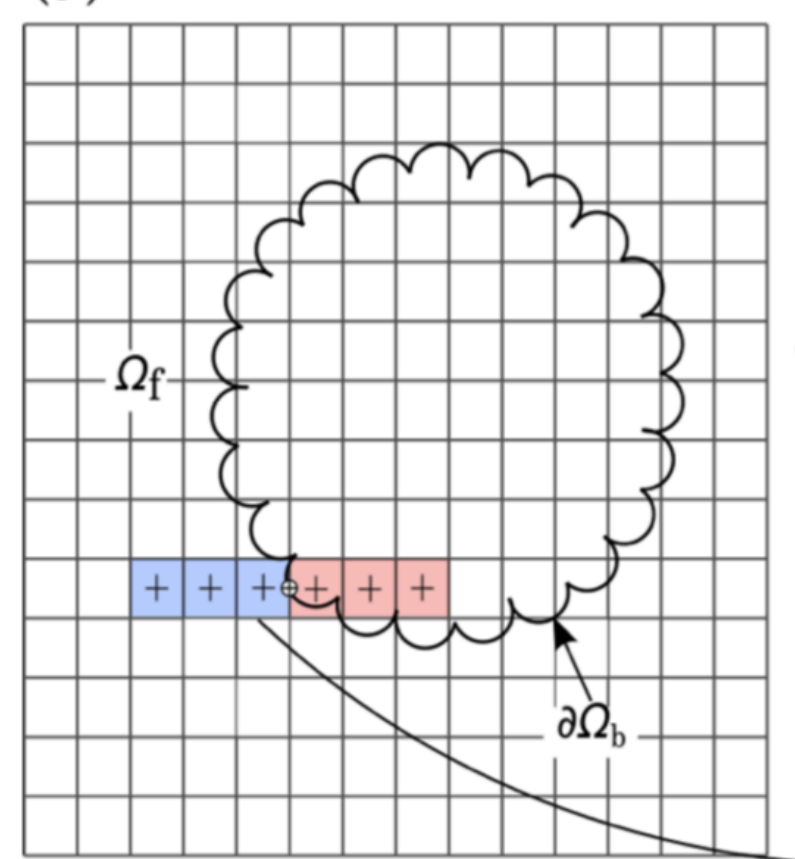

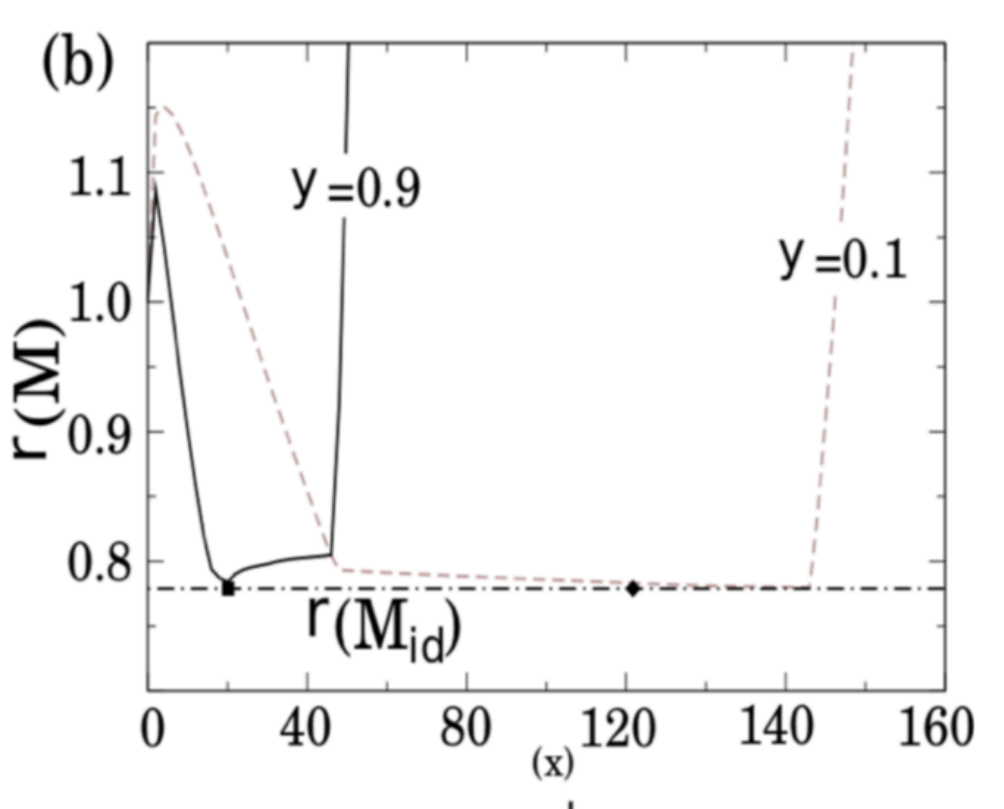

\begin{tabular}{l|l} 
(c) fluid & fluid \\
$++++\phi+++$
\end{tabular} discontinuities 


\section{Higher-Order IBM}

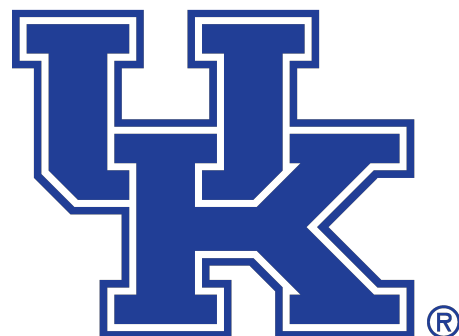

$\square$ 'Sharp' classification comes from boundary conditions being enforced directly at grid-line intersection points

$\square$ Advantageous for thin geometries

- No valid data is needed inside the geometry

- Now need to deal with freshly-cleared cells (FCCs)

$\square$ FCCs have no valid-time history

- Must interpolate from the surrounding flow

- Use canonical ENO selection in high-speed flows

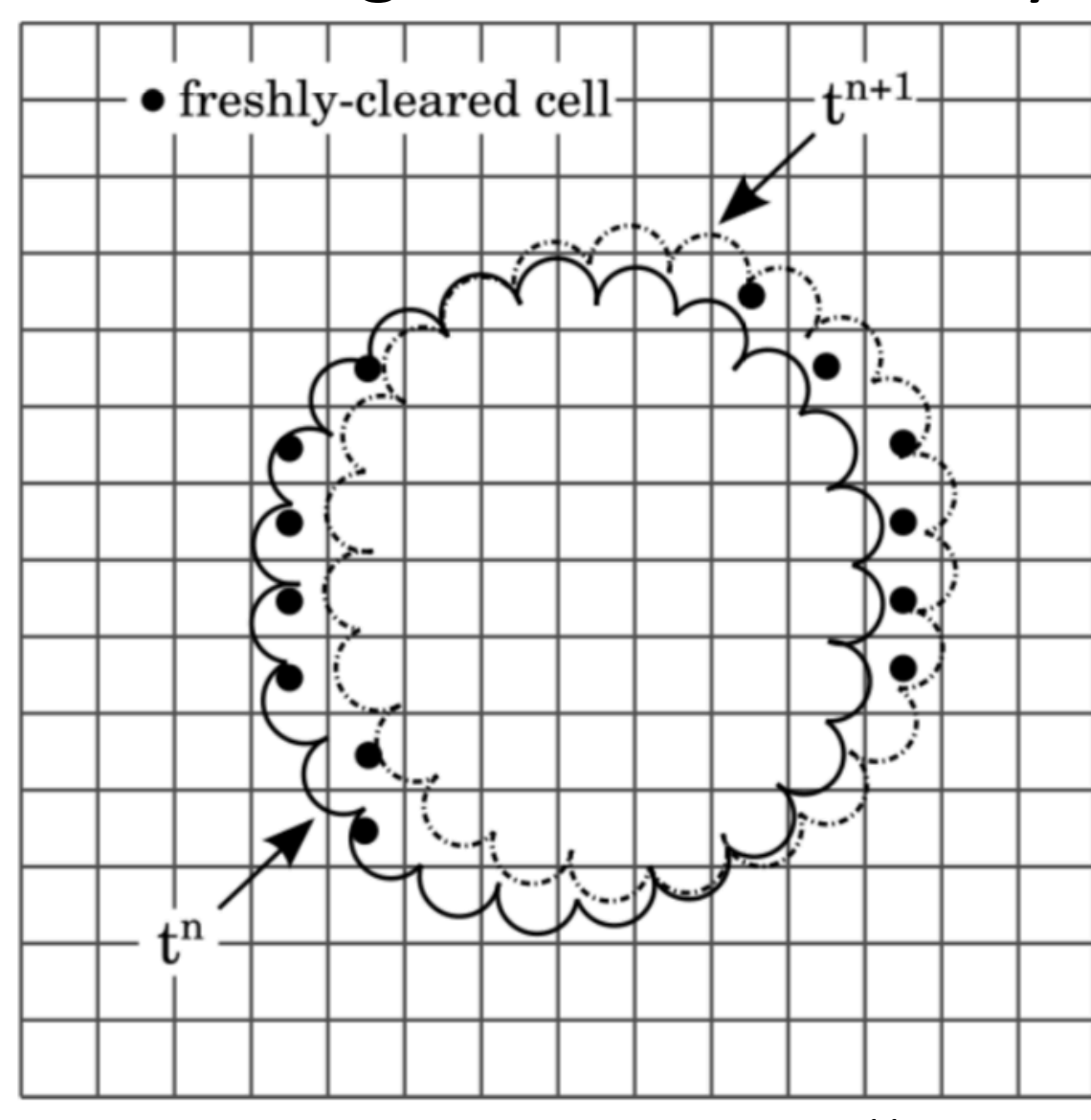

11 


\section{Structural Solver}

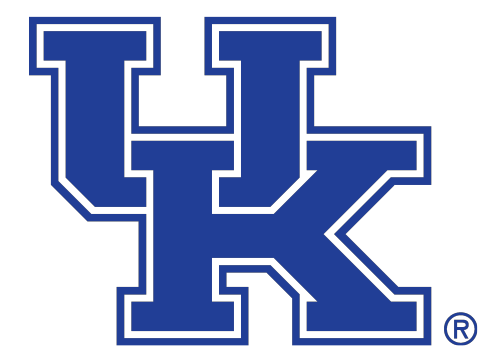

$\square$ Element formulations used:

o Geometrically nonlinear MITC3 triangular shell element

o Geometrically nonlinear generic cable element

$\square$ In this work, the St. Venant-Kirchoff hyperelastic strainenergy function is used

$\square$ Time integration is performed with the implicit Newmark- $\beta$ scheme

o Nonlinear solution is obtained via Newton-Raphson iteration 


\section{CFD-CSD Coupling}

$\square$ The CFD and CSD solvers are weakly coupled

$\circ$ The solution procedure is partitioned

An auxiliary and mass-less, or phantom, representation of the geometry with a finite thickness is used in the CFD solver

$\square$ The coupling conditions are enforced at the artificial interface between the geometry representation and the infinitesimal thickness CSD mesh

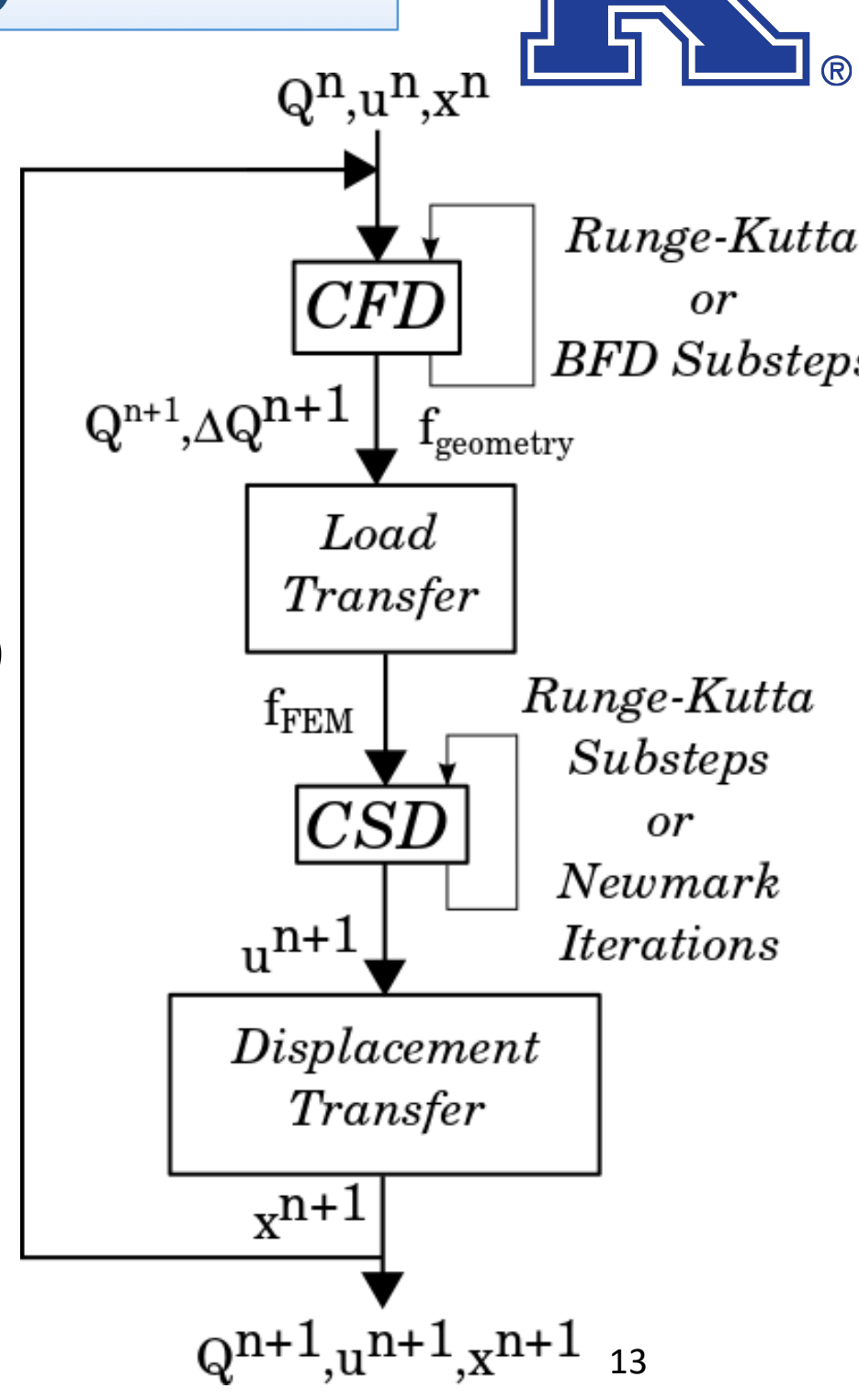




\section{CFD-CSD Coupling}

$\square$ The CFD and CSD solvers are weakly coupled

$\circ$ The solution procedure is partitioned

$\square$ An auxiliary and mass-less, or phantom, representation of the geometry with a finite thickness is used in the CFD solver

$\square$ The coupling conditions are enforced at the artificial interface between the geometry representation and the infinitesimal thickness CSD mesh

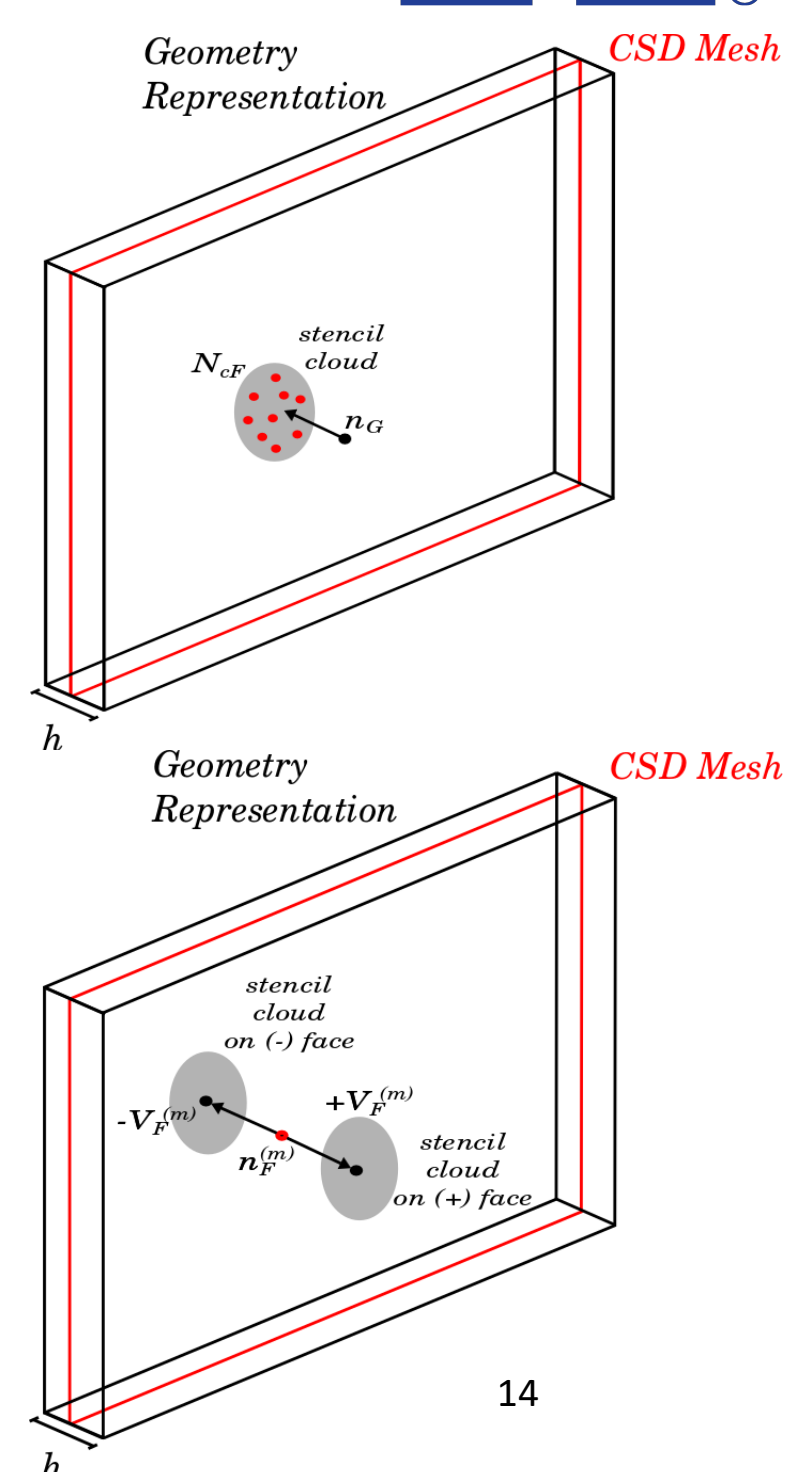




\section{Outline}

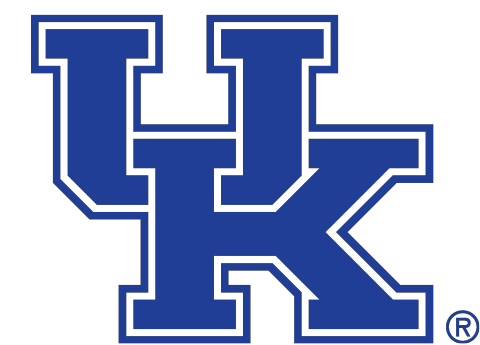

$\square$ Motivation/Introduction

o Mars, EDL system qualification, Simulation Capabilities

$\square$ FSI Method

○ Governing equations

- Immersed Boundary Method for the Compressible Navier-Stokes Equations (CFD)

- Geometrically Nonlinear Computational Structural Dynamics Solver (CSD)

- Coupling procedure

$\square$ Extended Validation for Fluid-Structure Interaction Problems

$\square$ Methods for Large-scale, Parallel CFD-CSD Coupling

o Disparate domain decomposition

$\square$ Supersonic Parachute Inflation

$\square$ Summary and Outlook 


\section{Bending of a Vertical Plate in Crossflow}

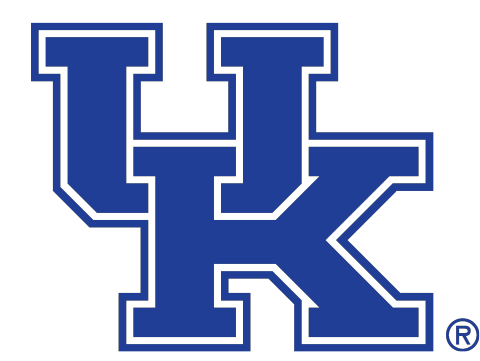

$\square$ Vertical plate of height $\mathrm{H}$ is clamped along bottom edge

$\square$ All parameters chosen in accordance with

o Simulations: Hu and Wang (JAFM 2016), and Seidel et al. (AIAA 2018)

o Experiments: Womack and Seidel (AIAA 2014), and Siefers et al. (AIAA 2018)

Exposed to viscous crossflow $\mathbf{U}=(U, 0,0)^{T}$

$\square$ Domain: $[-2 \mathrm{OH}, 25 \mathrm{H}] \times[-9 \mathrm{H}, 9 \mathrm{H}] \times[0,9 \mathrm{H}]$

$\square \Delta x_{\text {min }}=\Delta y_{\text {min }}=\mathrm{H} / 25$

$\square$ No-slip wall on plate, slip wall on $x-y$ boundary

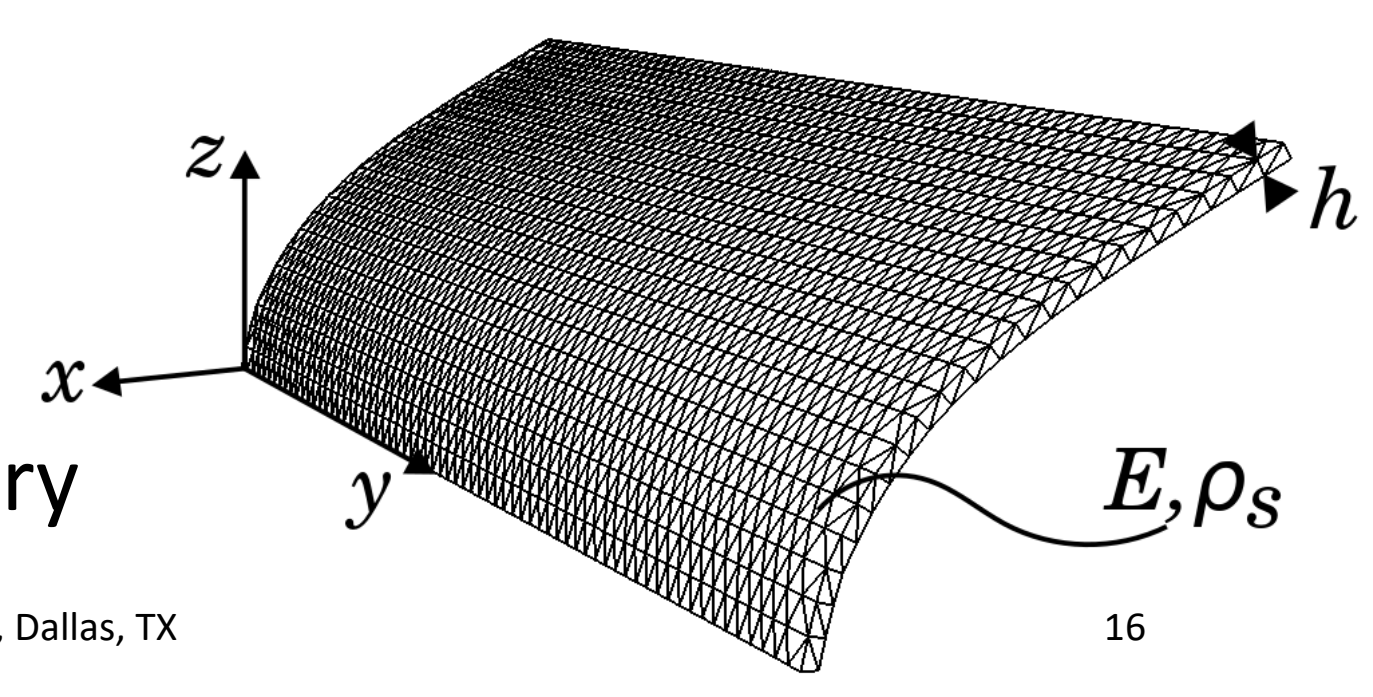


$\square$ For comparison with Hu and Wang (JAFM 2016) and Womack and Seidel (AIAA 2014), Siefers et al. (AIAA 2018) introduced the

1. Mean chord angle

$$
\varnothing=\tan ^{-1}\left(\frac{\delta_{x}}{H-\delta_{z}}\right)
$$

2. Normalized curvature

$$
k=\frac{q H^{3}}{E h^{3}}
$$

$\square$ These parameters reduce the solution to a single variable, $\varnothing$

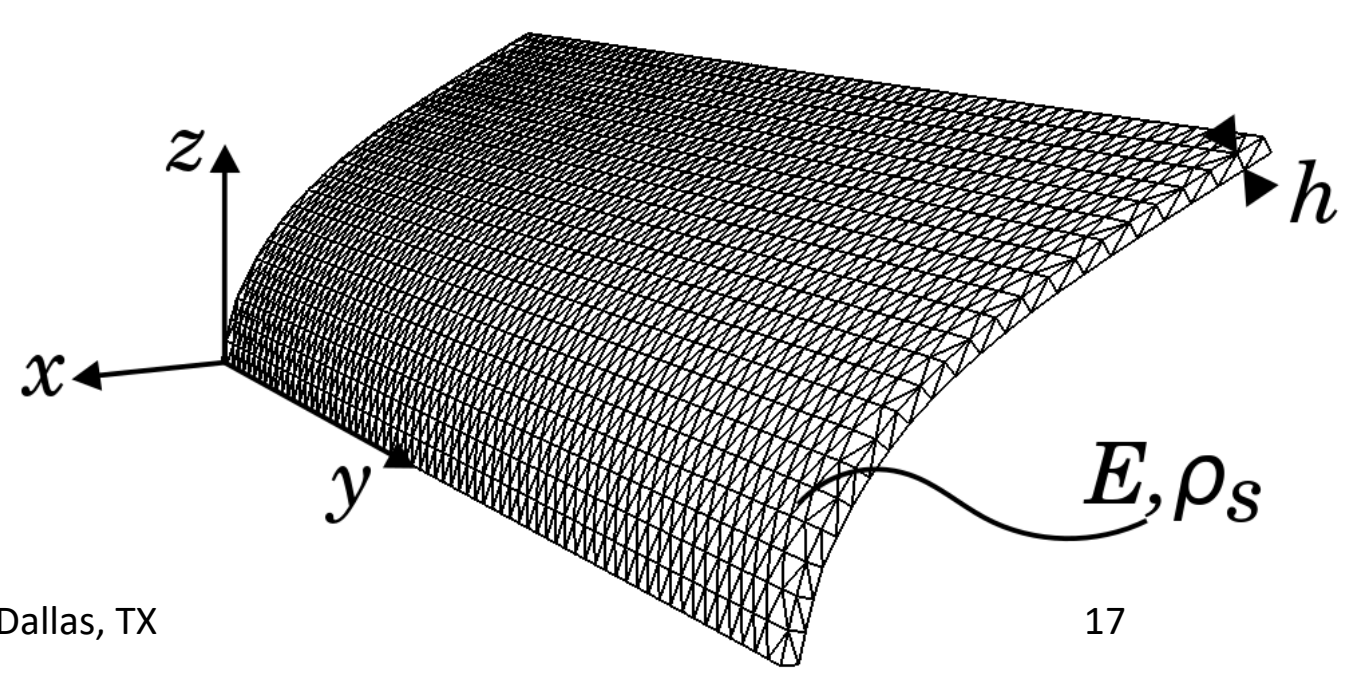




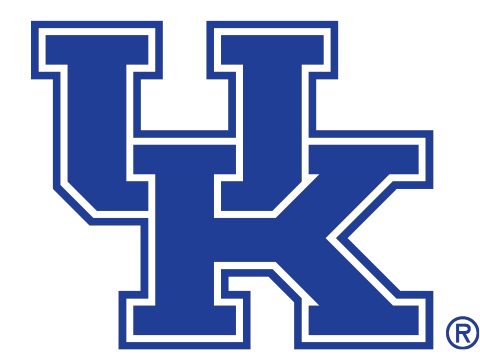

$\square$ Siefers et al. (AIAA 2018) notes that geometrically linear deformations become invalid after $k=0.3$

$\square$ As shown, the current method shows good agreement with established experiments and simulations

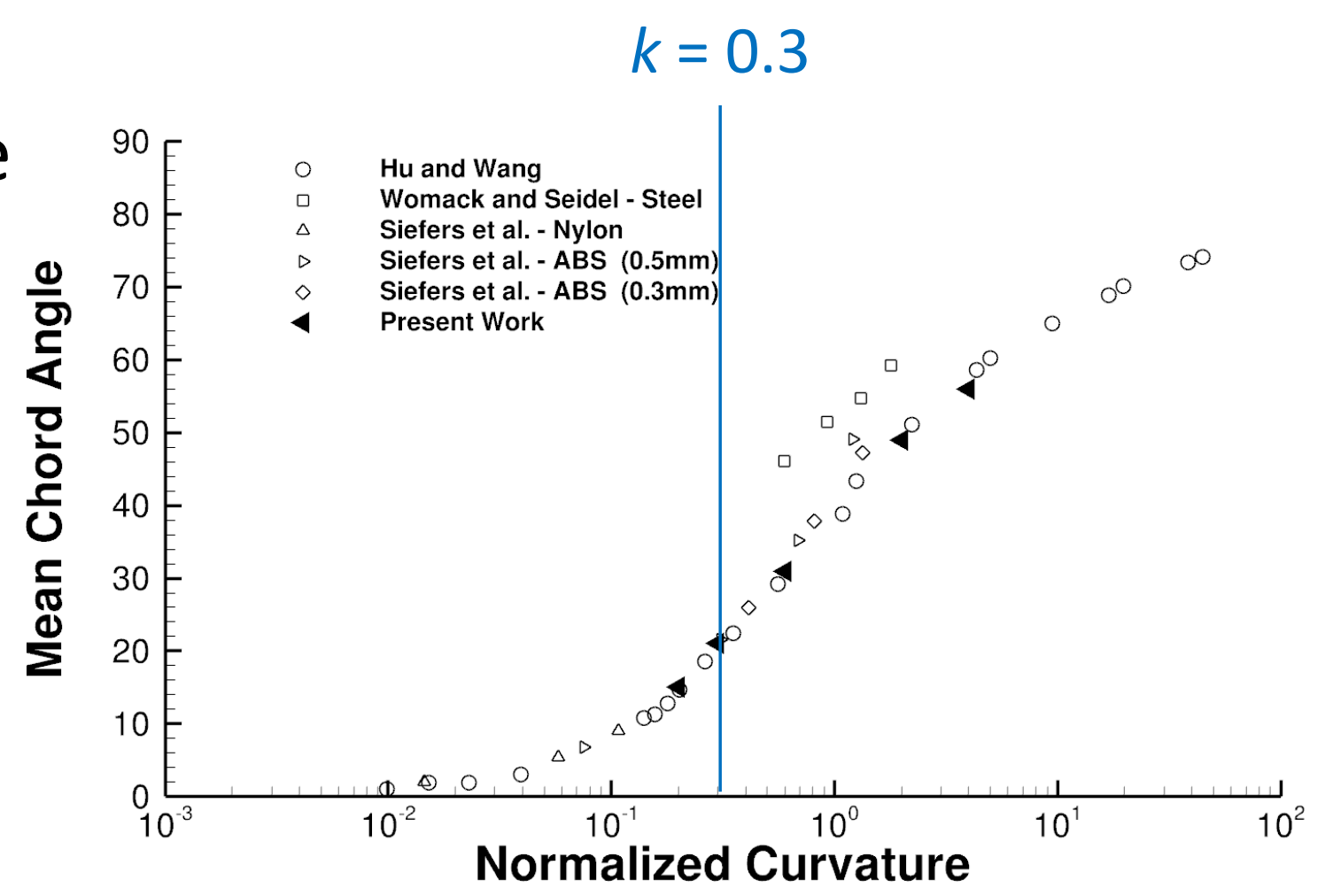

$\square$ Plate response becomes unsteady for larger values of $k$ 


\section{Streamwise Velocity}

$k=2.0$

0.0

$-1.5$

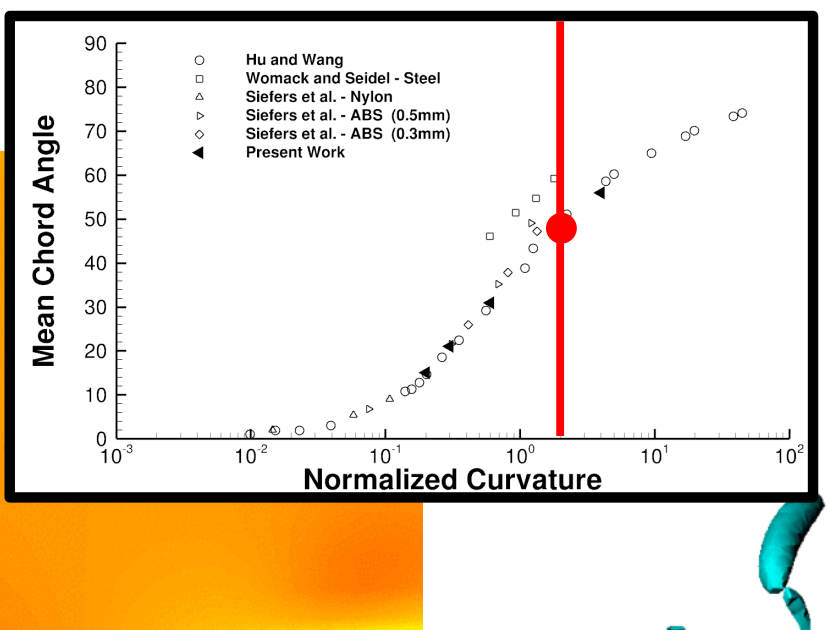

Q-Criterion $(Q=2,500)$

$k=2.0$

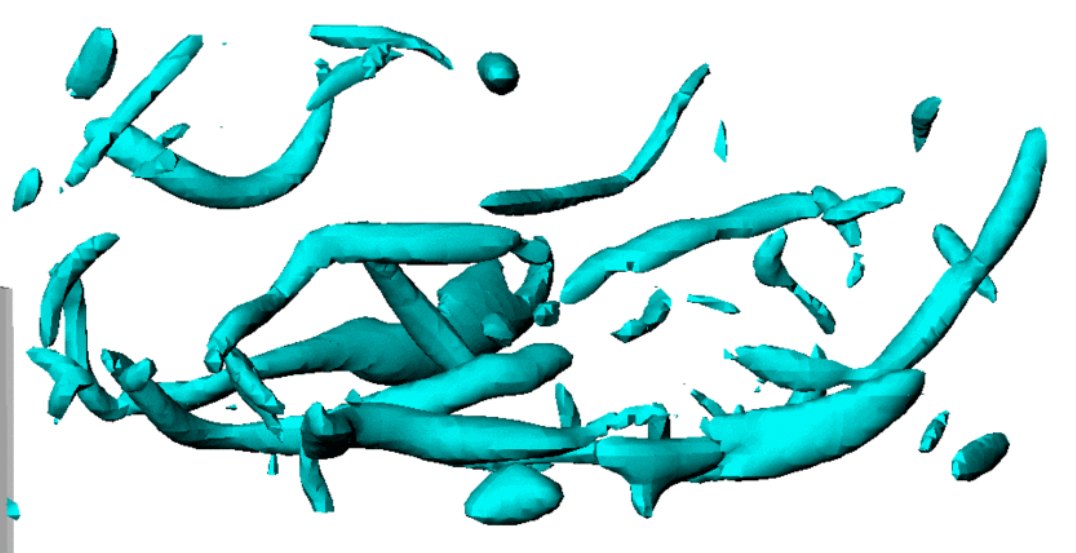




\section{Waving Flag}

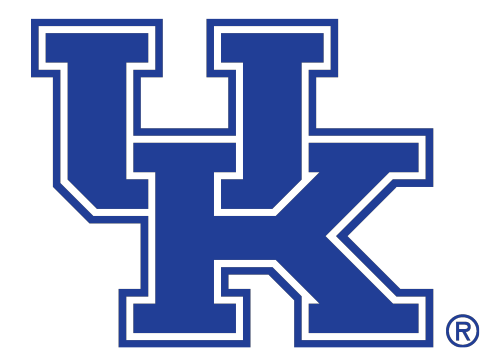

$\square$ Consider the setup chosen by Huang et al. (JFM 2010) and Hua et al. (JFM 2014)

$\circ R e=100$

$\circ \mathrm{MR}=\frac{\rho_{S} h}{\rho_{f} L}=100$

$\circ \Delta x_{\min }=\Delta y_{\min }=0.02 \mathrm{~L}$

o Discretized with 3,200 finite elements

$\circ$ FEM mesh is pinned at the leading edge

$\circ 18^{\circ}$ crossflow to induced motion

o Thickness, $h$, is 0.01

$\circ S_{\mathrm{s}}=\frac{E I_{s}}{\rho_{f} U^{2} L^{3}}=1 \times 10^{3}$,

$\circ S_{b}=\frac{E h}{\rho_{f} U^{2} L}=1 \times 10^{-4}$

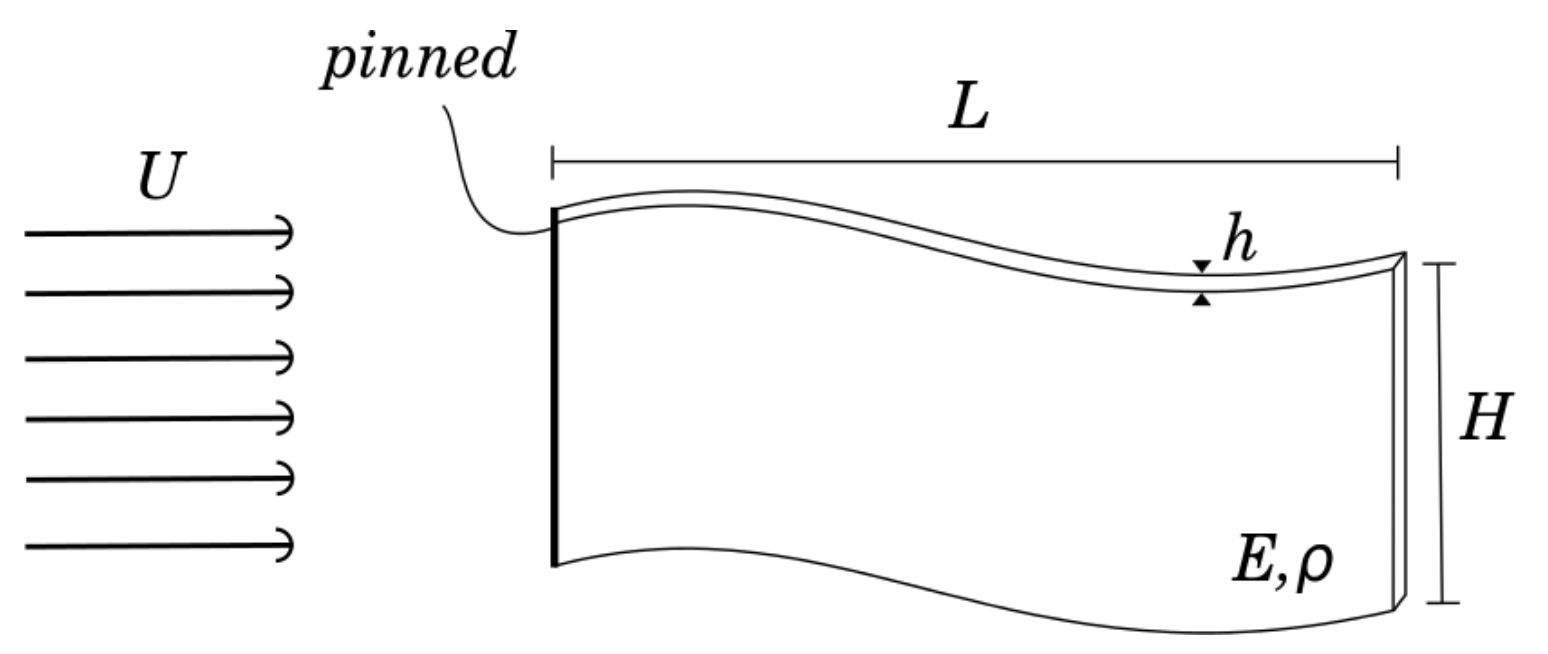




\section{Waving Flag}

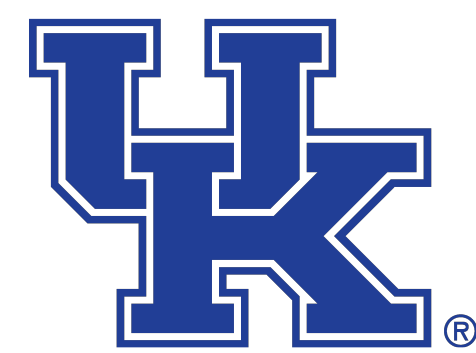

\begin{tabular}{c|c|c} 
Reference & $\overline{\mathbf{A}}$ & St \\
\hline Present Work & 0.57 & 0.22 \\
\hline Huang et al. (JFM 2010) & 0.58 & 0.24 \\
\hline Hua et al. (JFM 2014) & 0.58 & 0.24
\end{tabular}

$\square$ As shown, good agreement is obtained both in terms of the excursion amplitude $\frac{\left(\delta_{z, \max }-\delta_{z, \min }\right)}{L}$ and the Strouhal number $f \frac{U}{L}$

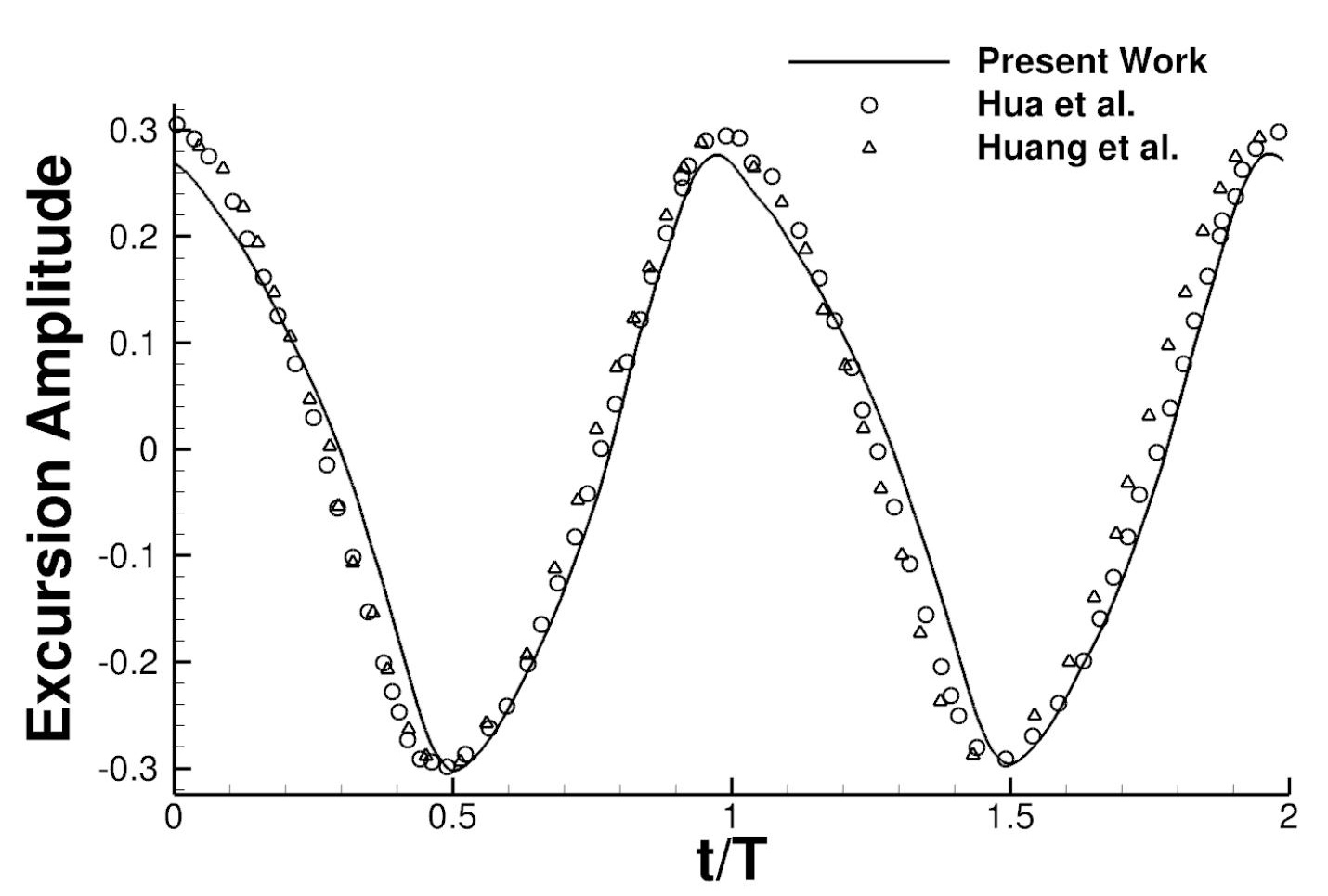




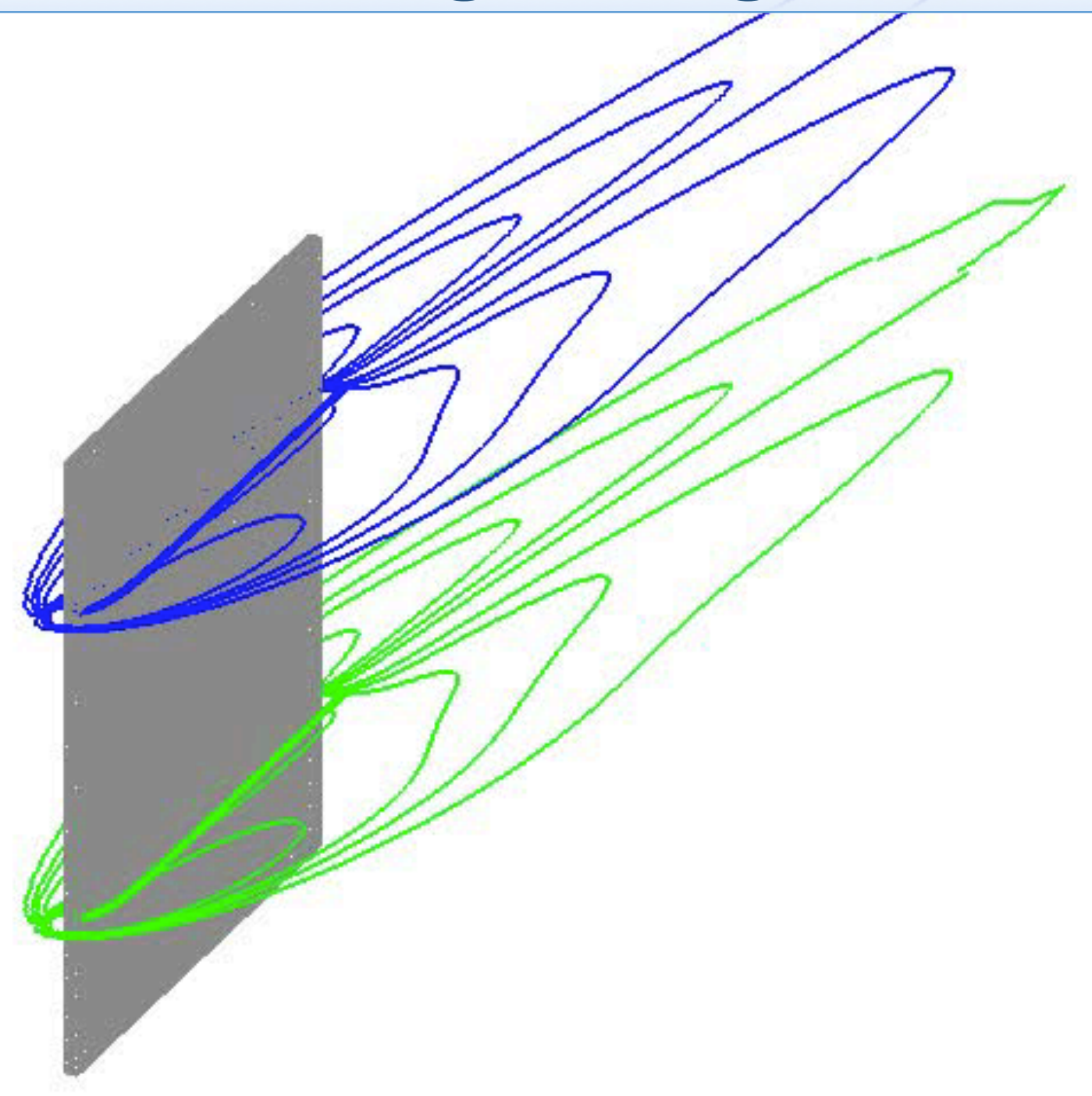




\section{Outline}

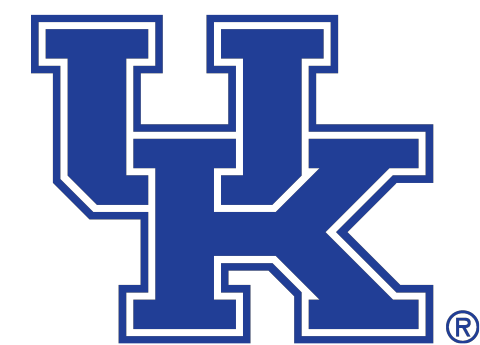

$\square$ Motivation/Introduction

o Mars, EDL system qualification, Simulation Capabilities

$\square$ FSI Method

○ Governing equations

- Immersed Boundary Method for the Compressible Navier-Stokes Equations (CFD)

- Geometrically Nonlinear Computational Structural Dynamics Solver (CSD)

○ Coupling procedure

$\square$ Extended Validation for Fluid-Structure Interaction Problems

$\square$ Methods for Large-scale, Parallel CFD-CSD Coupling

o Disparate domain decomposition

$\square$ Supersonic Parachute Inflation

$\square$ Summary and Outlook 
$\square$ In Boustani et al. SciTech 2019, the structures consisted of a few thousand shell elements

o This allowed a parallel CFD - serial CSD coupling

$\square$ When considering a parachute geometry, the number of degrees of freedom requires parallel computing

- The parallel CFD - parallel CSD coupling requires a complex communication pattern

$\circ$ When dealing with large-scale problems, minimize memory and overhead

$\square$ What happens when the CFD and CSD partitions are disparate?

o Expected in weakly coupled FSI algorithms 


\section{Parallel FSI Algorithm}

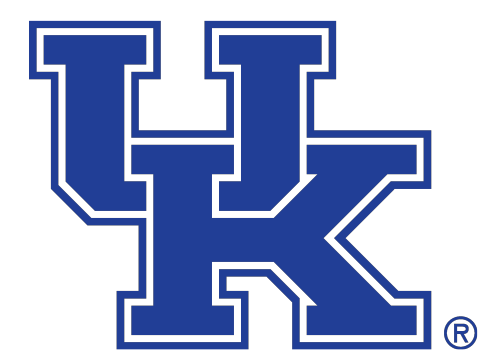

I. The CFD solver uses an octree data structure to organize the volume data $\circ$ The geometry representation is partitioned accordingly

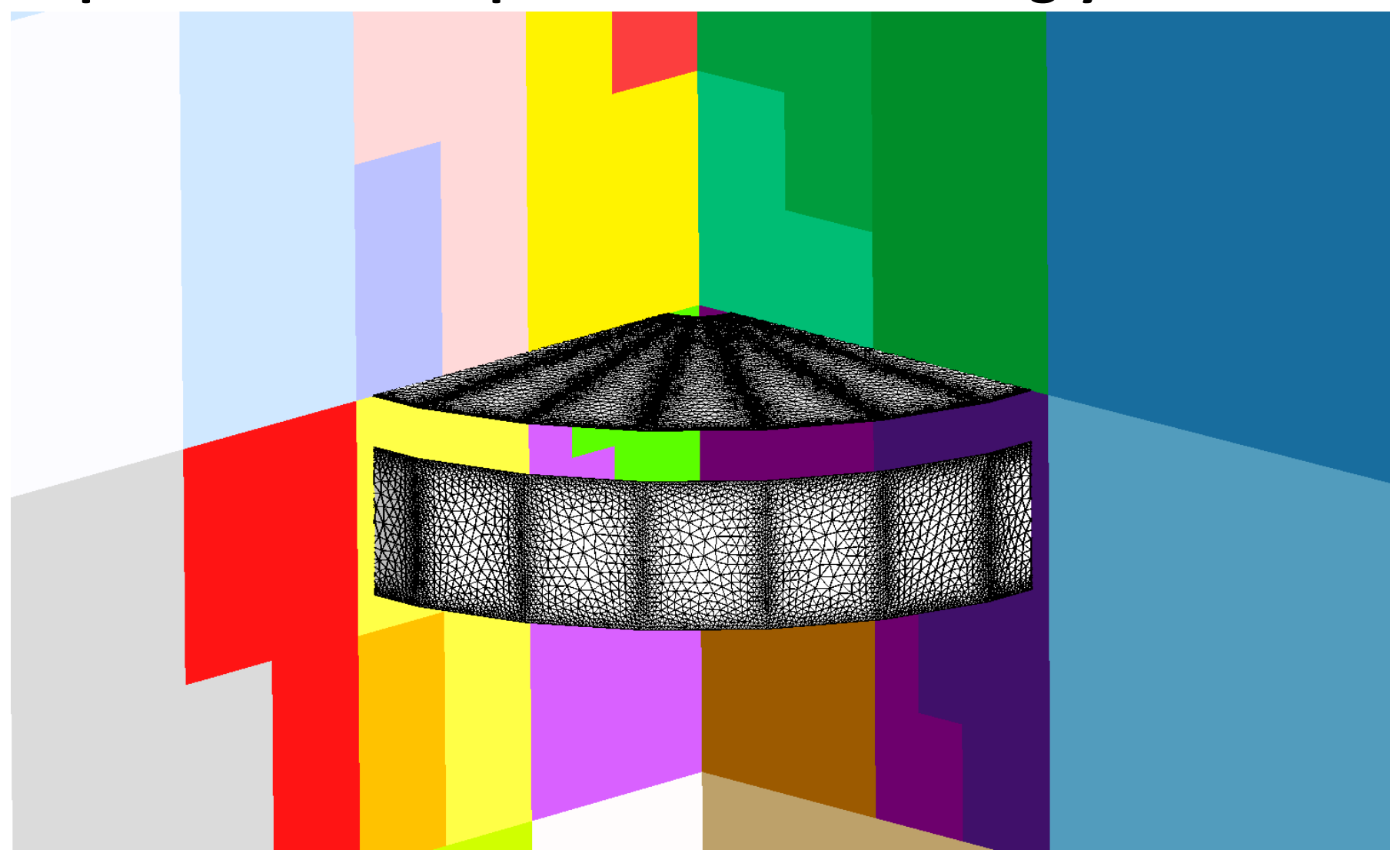




\section{Parallel FSI Algorithm}

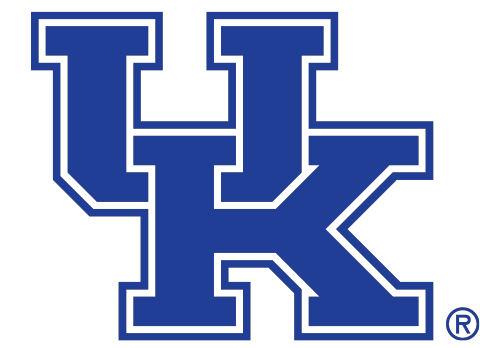

II. The CSD solver is partitioned on an unstructured mesh by ParMETIS

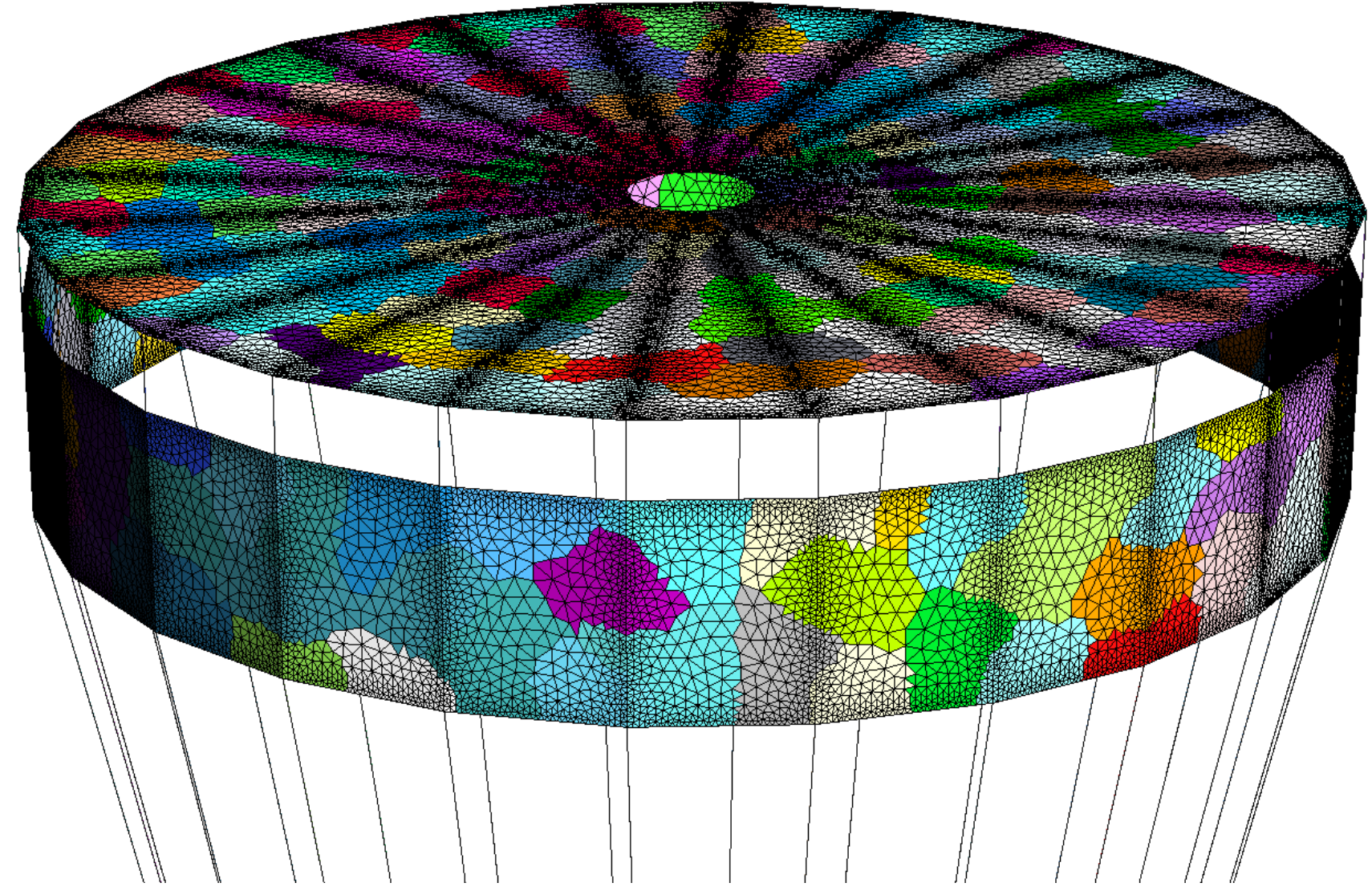




\section{Parallel FSI Algorithm}

\section{Aside:}

$\square$ How does process ' $m$ ' get/transfer loads/displacements to/from process ' $n$ '? 


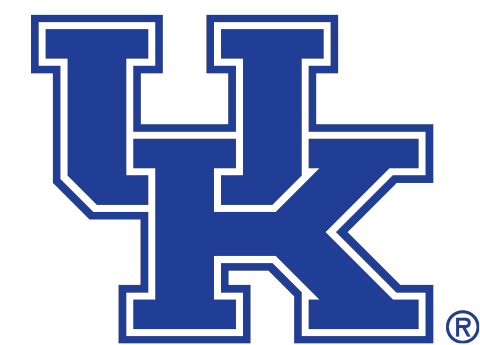

\section{Aside:}

$\square$ How does process ' $m$ ' get/transfer loads/displacements to/from process ' $n$ '?

$\square$ Decompose geometry representation from the CSD solver as well

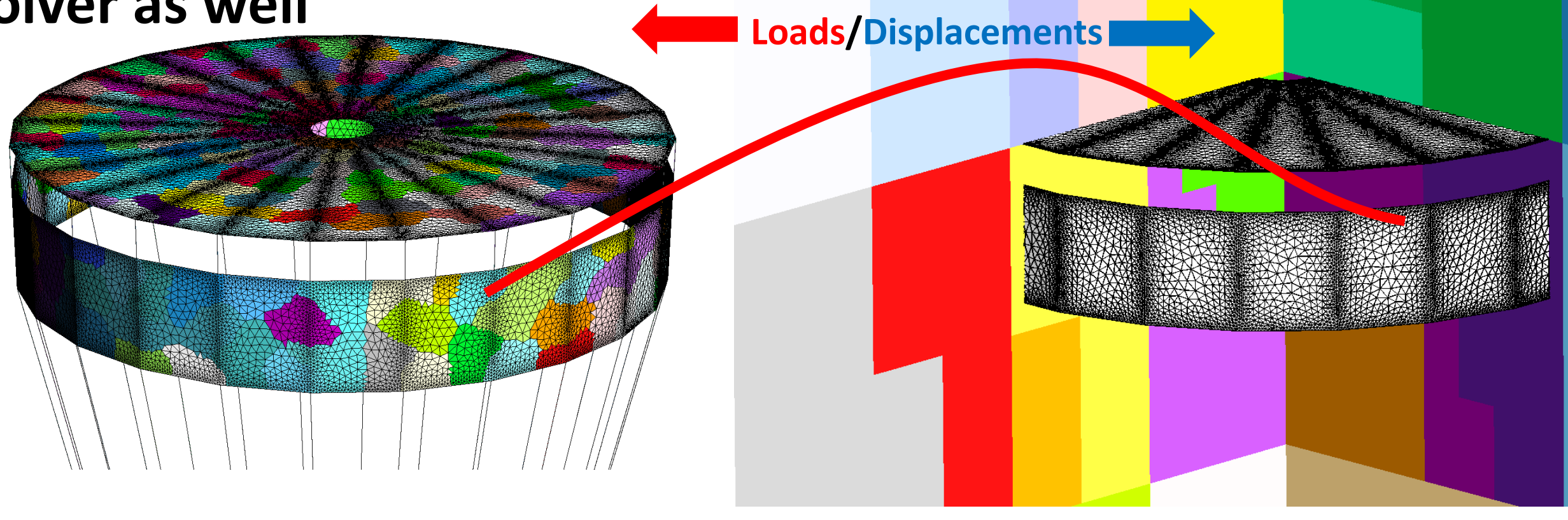




\section{Parallel FSI Algorithm}

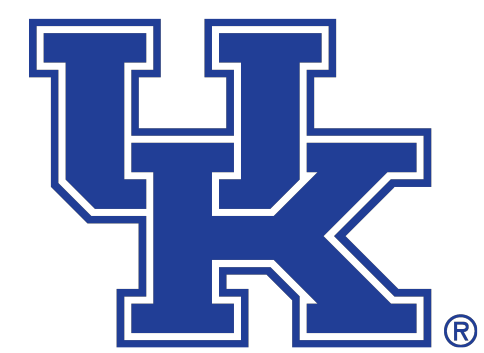

\section{Aside:}

$\square$ Ray-triangle intersection is used to identify elements in the geometry representation laying directly 'above/below' a CSD partition

o Ray intersect a CSD element belonging to a partition and are stored uniquely by that partition

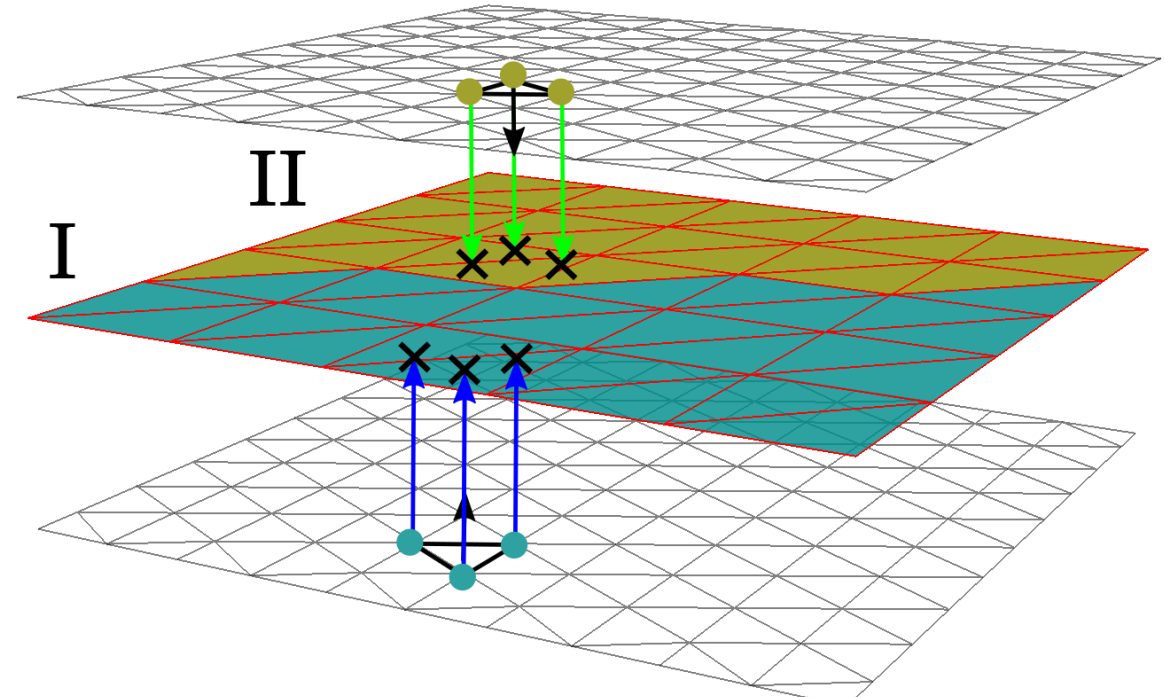




\section{Parallel FSI Algorithm}

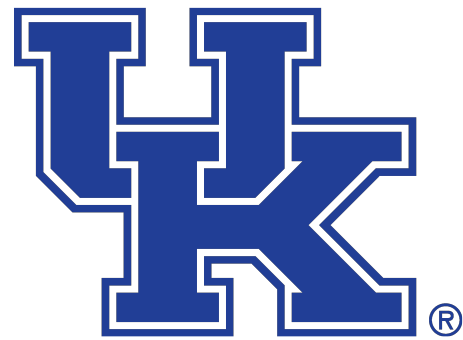

III. Load and displacement transfer stencils are computed between the geometry representation and CSD mesh within the defined partitions

o Stencils are limited a single partition

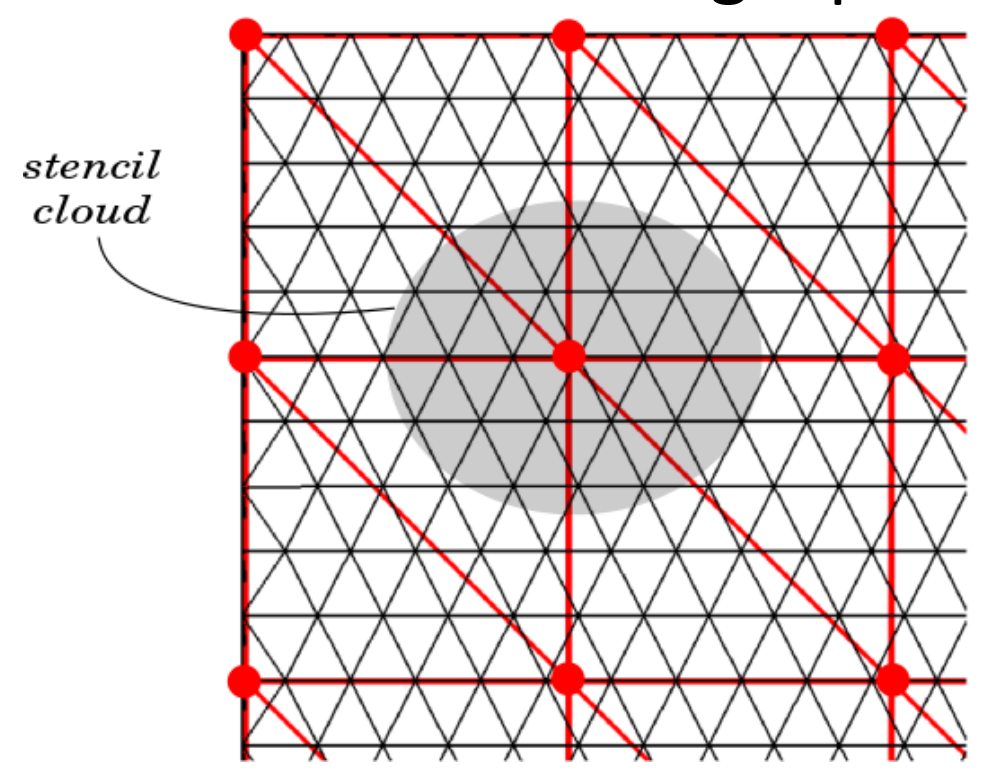

Serial CSD Displacement Stencil

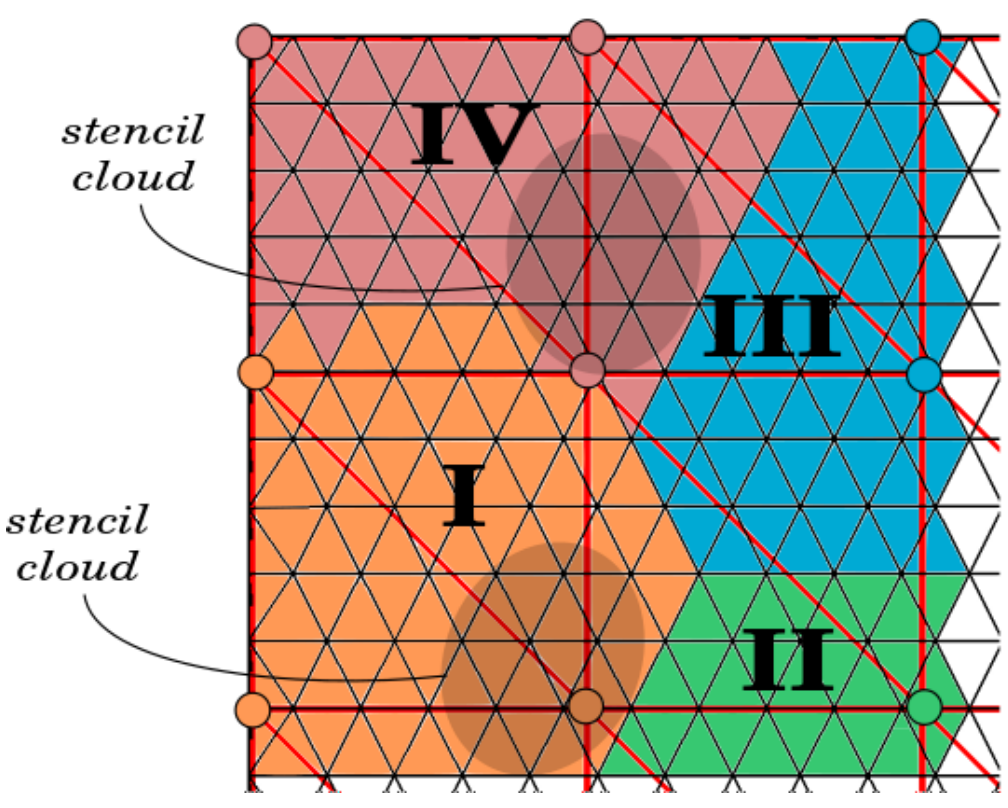

Parallel CSD Displacement Stencil 


\section{Parallel FSI Algorithm}

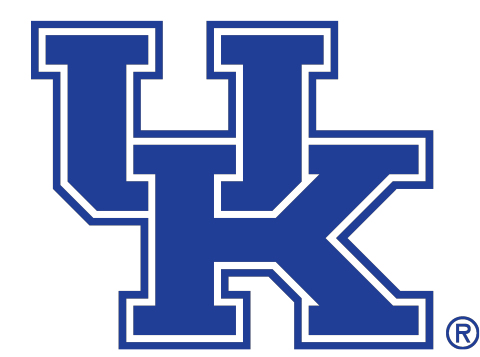

$\square$ Using this algorithm, each process only stores its portion(s) of the CFD volume mesh, geometry representation, and the CSD mesh

o Need to communicate to other processors is reduced greatly

o Memory requirements are less demanding

$\square$ It is clear that the geometry representation is stored twice

o Once when partitioned by the CFD solver via volume decomposition

- Once when partitioned by the CSD solver via ray-triangle intersection

o No guarantee that these partitions are the same

$\square$ Best case scenario is a shared, infinitesimal thickness representation of the CSD mesh and geometry representation 


\section{Outline}

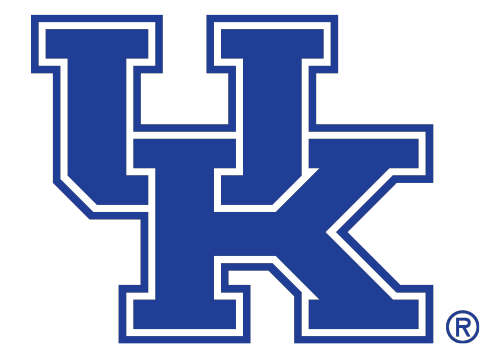

$\square$ Motivation/Introduction

o Mars, EDL system qualification, Simulation Capabilities

$\square$ FSI Method

○ Governing equations

- Immersed Boundary Method for the Compressible Navier-Stokes Equations (CFD)

○ Geometrically Nonlinear Computational Structural Dynamics Solver (CSD)

○ Coupling procedure

$\square$ Extended Validation for Fluid-Structure Interaction Problems

$\square$ Methods for Large-scale, Parallel CFD-CSD Coupling

o Disparate domain decomposition

\section{$\square$ Supersonic Parachute Inflation}

$\square$ Summary and Outlook 


\section{Problem Setup}

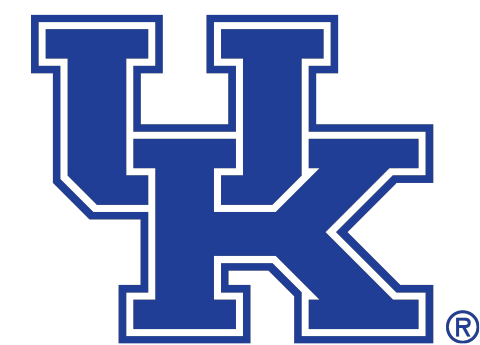

$\square$ Setup is chosen in accordance with

o Experiments: Sengupta et al. (AIAA 2009)

o Simulations: Karagiozis et al. (JFS 2011) and Yu et al. (AIAA 2019)

$\square 0.8 \mathrm{~m} D_{0}$ DGB Parachute design is based off Reuter et al. (AIAA 2009)

$\circ$ Sub-scale Viking parachute model with and without a sub-scale $70^{\circ}$ Viking capsule

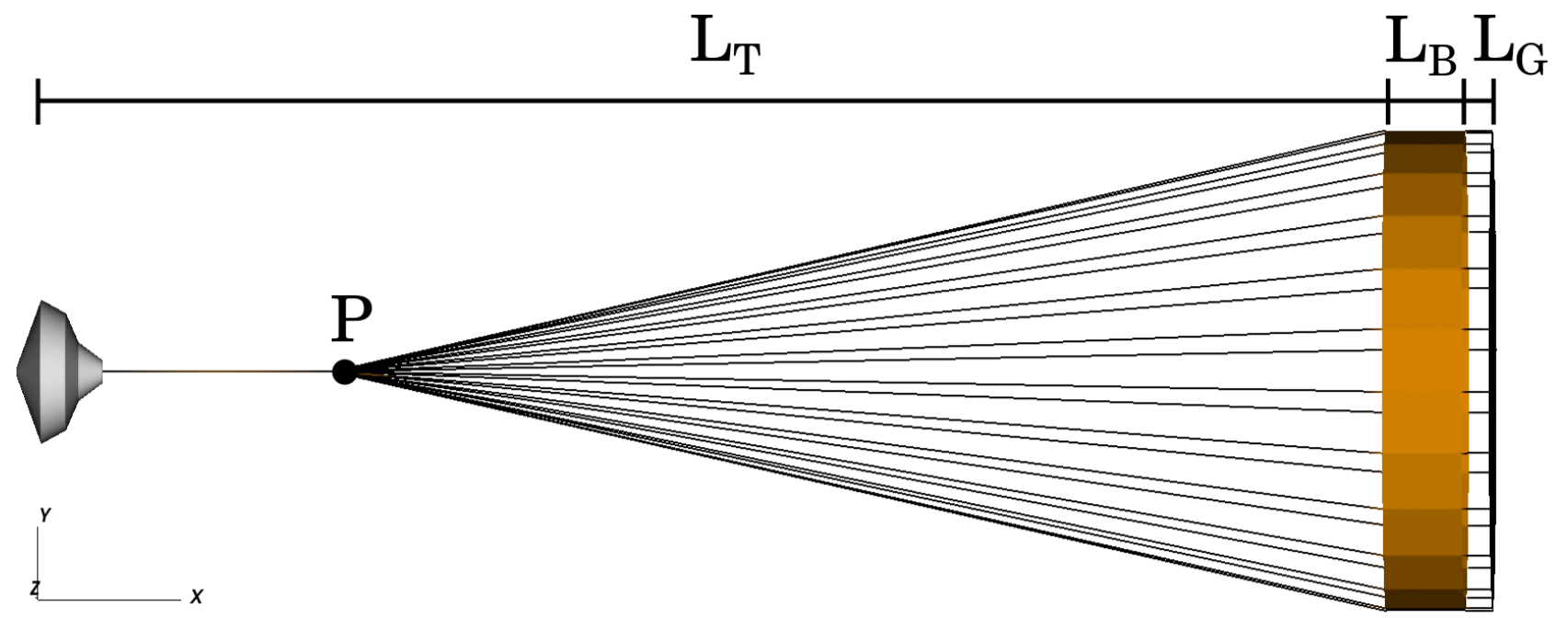

\begin{tabular}{c|c|c}
$\mathrm{L}_{\mathrm{T}}$ & $\mathrm{L}_{\mathrm{B}}$ & $\mathrm{L}_{\mathrm{G}}$ \\
$\frac{\boldsymbol{x}}{\boldsymbol{d}}=\mathbf{1 0 . 6}$ & $\mathbf{0 . 1 2 1 D _ { 0 }}$ & $\mathbf{0 . 0 4 2} D_{0}$
\end{tabular}




\section{Problem Setup}

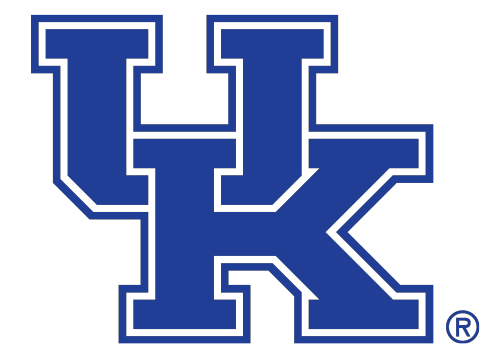

$\square$ Setup is chosen in accordance with

o Experiments: Sengupta et al. (AIAA 2009)

o Simulations: Karagiozis et al. (JFS 2011) and Yu et al. (AIAA 2019)

$\square 0.8 \mathrm{~m} D_{0}$ DGB Parachute design is based off Reuter et al. (AIAA 2009)

$\circ$ Sub-scale Viking parachute model with and without a sub-scale $70^{\circ}$ Viking capsule

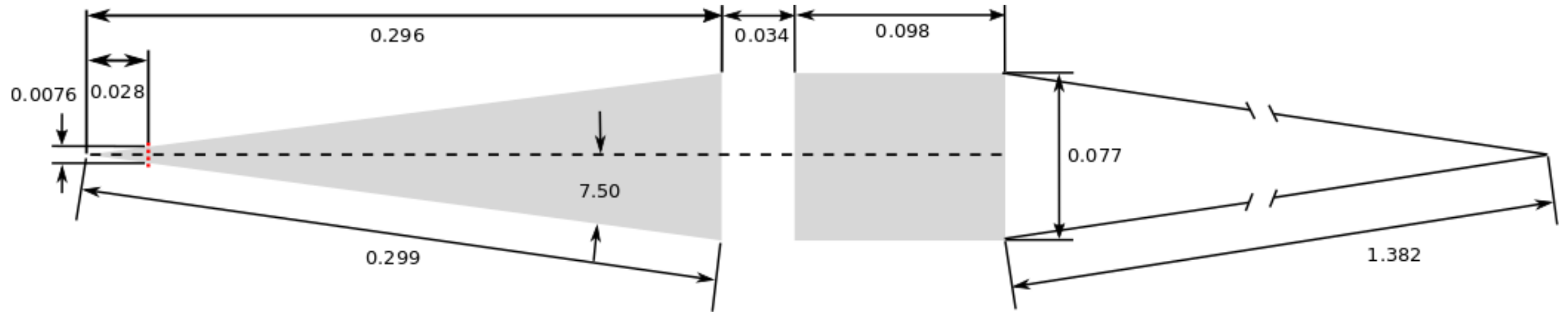


$\square$ Problem resembles spacecraft entry into the upper Martian atmosphere:

\section{Fluid Properties}

$\square R e=\frac{\rho_{\infty} u_{\infty} d}{\mu_{\infty}}=10^{5}$

$\square \mu_{\infty}$ via Sutherland's law at $T_{\infty}=$ $294.93 K$

$\square \rho_{\infty}=0.0184527 \frac{\mathrm{kg}}{\mathrm{m}^{3}}$

$\square u_{\infty}=688.89 \frac{\mathrm{m}}{\mathrm{s}}$

$\square M=\frac{u_{\infty}}{a_{\infty}}=2.0$
Structural Properties

$$
\begin{aligned}
& \square E_{p}=878 \mathrm{MPa} \\
& \square v=0.33 \\
& \square h=6.35 \times 10^{-5} \mathrm{~m} \\
& \square \rho_{p}=614 \frac{\mathrm{kg}}{\mathrm{m}^{3}} \\
& \square d_{c}=0.99 \times 10^{-3} \mathrm{~m} \\
& \square E_{c}=43 G P a \\
& \square \rho_{c}=8.27 \times 10^{-4} \frac{\mathrm{kg}}{\mathrm{m}}
\end{aligned}
$$


$\square$ Center of the vent hole is at $(0,0,0)$

$\square$ Domain: $\left[-6.25 D_{0}, 6.25 D_{0}\right] \times\left[-6.25 D_{0}, 6.25 D_{0}\right] \times\left[-6.25 D_{0}, 6.25 D_{0}\right]$

$\square$ Base case: $\Delta x_{\min }=\Delta y_{\min }=D_{0} / 164$

$\square 60$ geometrically nonlinear cables elements are used for the suspension lines $\circ$ Fixed at point $P$

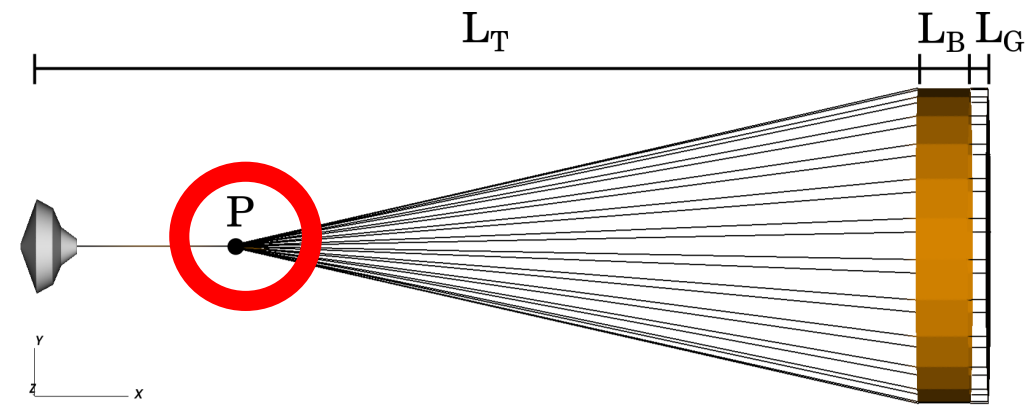

$\square$ 108,000 geometrically nonlinear shell elements resolve the disk and canopy 
$\square$ Center of the vent hole is at $(0,0,0)$

$\square$ Domain: $\left[-6.25 D_{0}, 6.25 D_{0}\right] \times\left[-6.25 D_{0}, 6.25 D_{0}\right] \times\left[-6.25 D_{0}, 6.25 D_{0}\right]$

$\square$ Base case: $\Delta x_{\min }=\Delta y_{\min }=D_{0} / 164$

$\square 600$ geometrically nonlinear cables elements are used for the suspension lines $\circ$ Fixed at point $P$

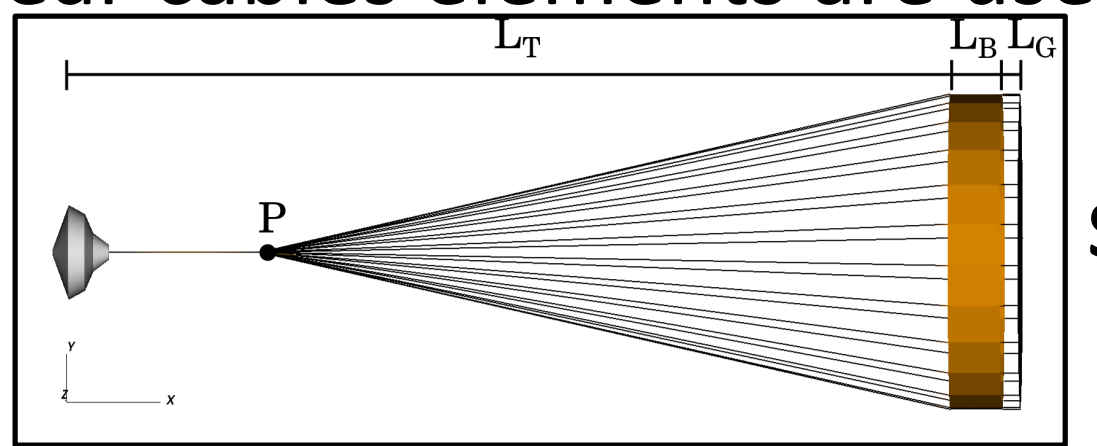

Simulation initial condition

$\square$ 108,000 geometrically nonlinear shell elements resolve the disk and canopy 


\section{Problem Setup}

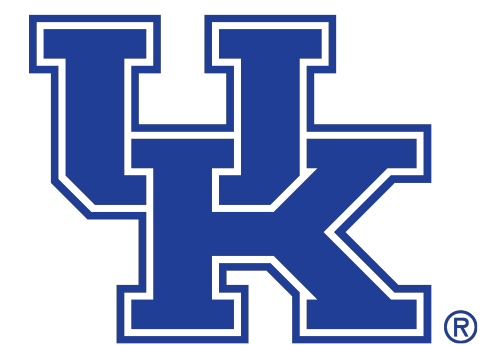

- Structural mesh based off simulations by Derkevorkian et al. (AIAA 2019)

$\circ$ Elements along seams are thickened by a factor of 4 to represent the stitching pattern used in manufacturing of the canopy

o Finely resolving these regions also helps capture the stress discontinuities across the seams

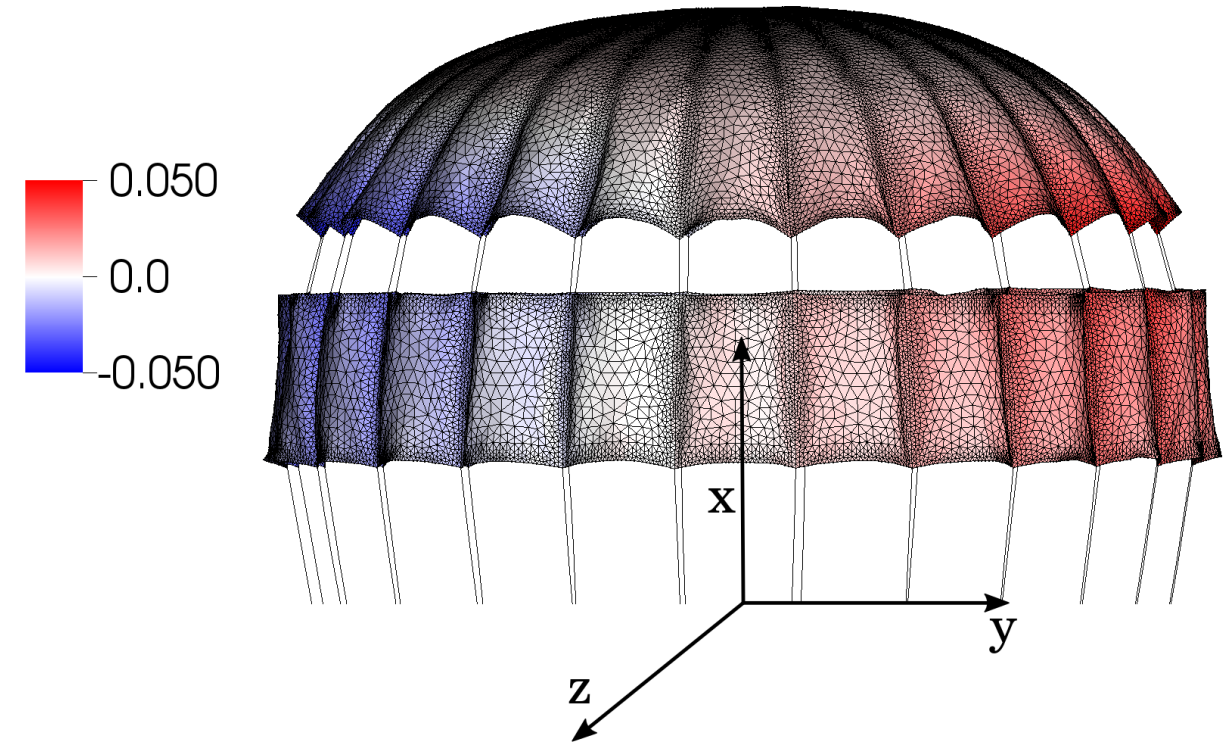




\section{Case 1: Uniform Flow (no capsule)}

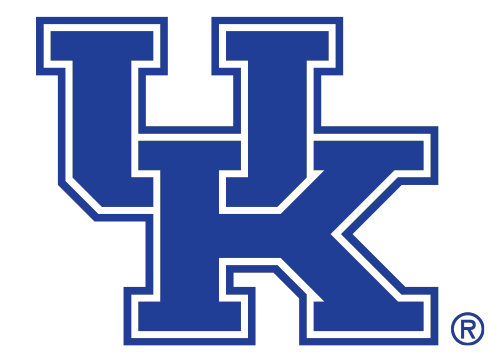

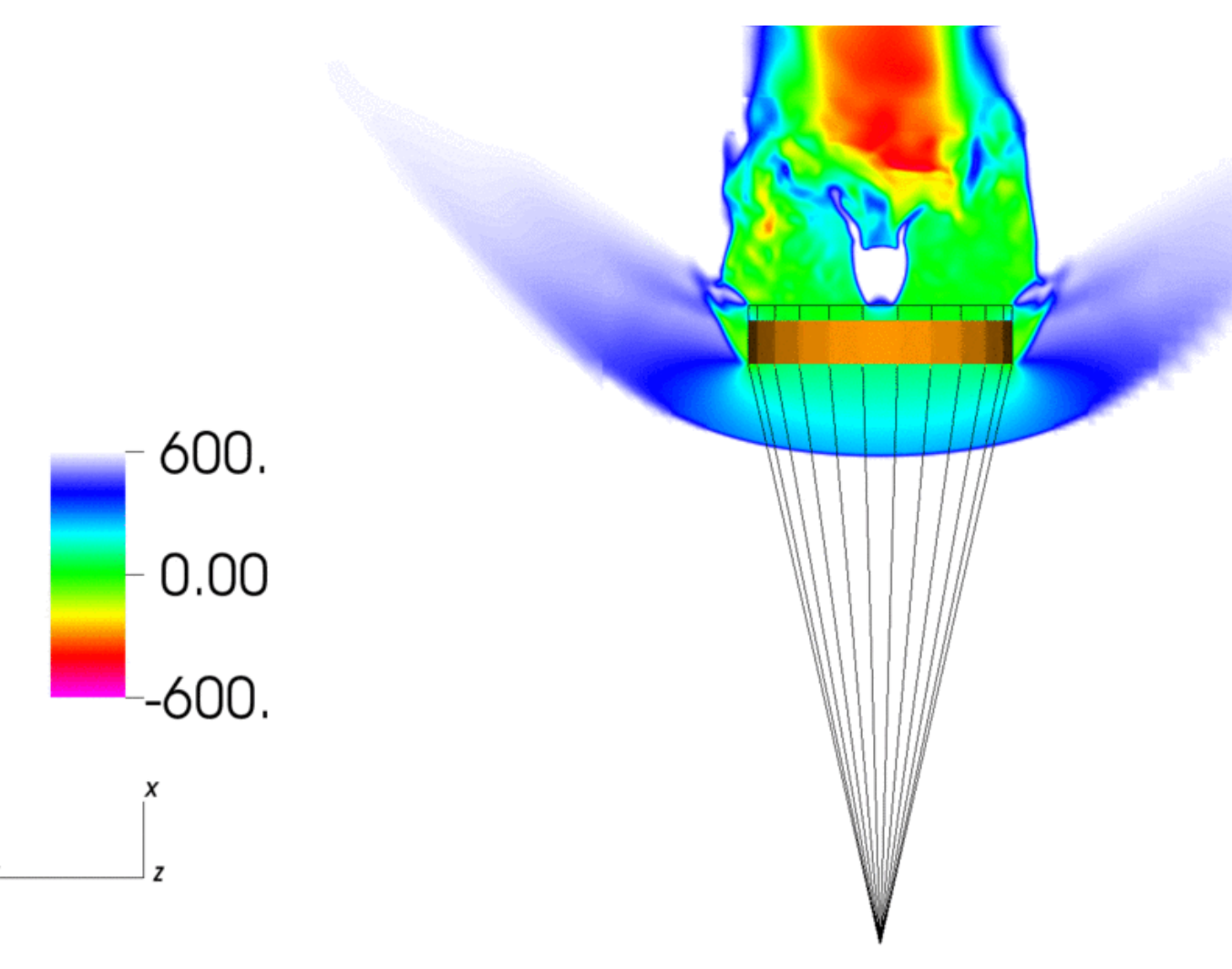

Streamwise velocity

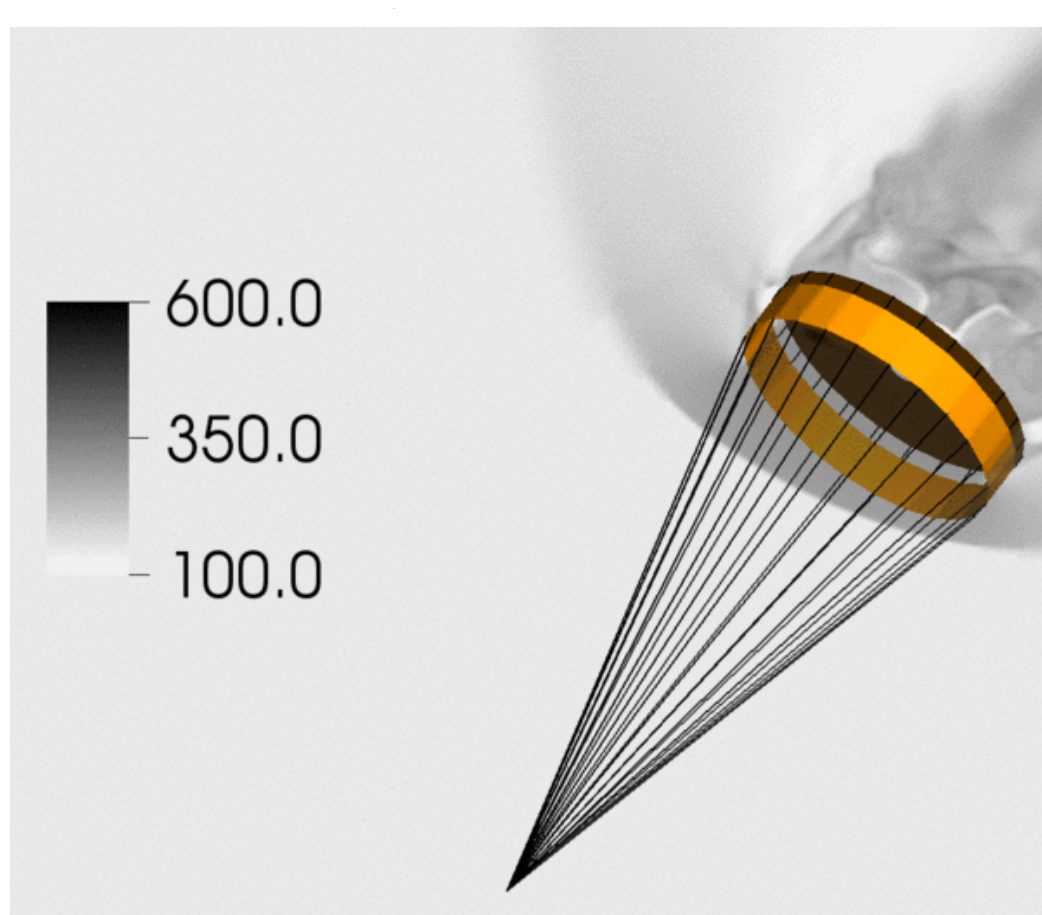

Temperature field 


\section{Case 1: Uniform Flow (no capsule)}

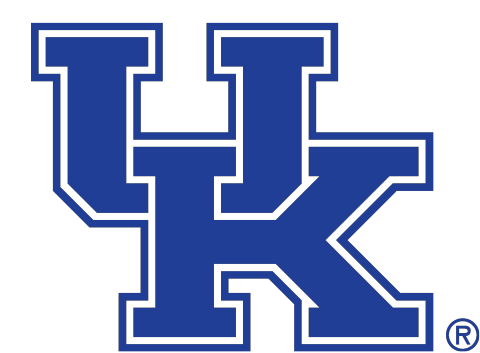

$\square$ The cables are not resolved in the CFD volume mesh

$\circ$ Nor do they experience any external loading $\rightarrow$ motion is virtually unopposed

o This leads to large period, large amplitude swaying of the cables

$\square$ The cables, as well as the canopy, start the simulation in an unstressed state

o There is no tension in the cables

$\square$ Resolve with phantom geometry or approximate ling drag from damping matrix, reduced order model, etc.? Pre-tension?

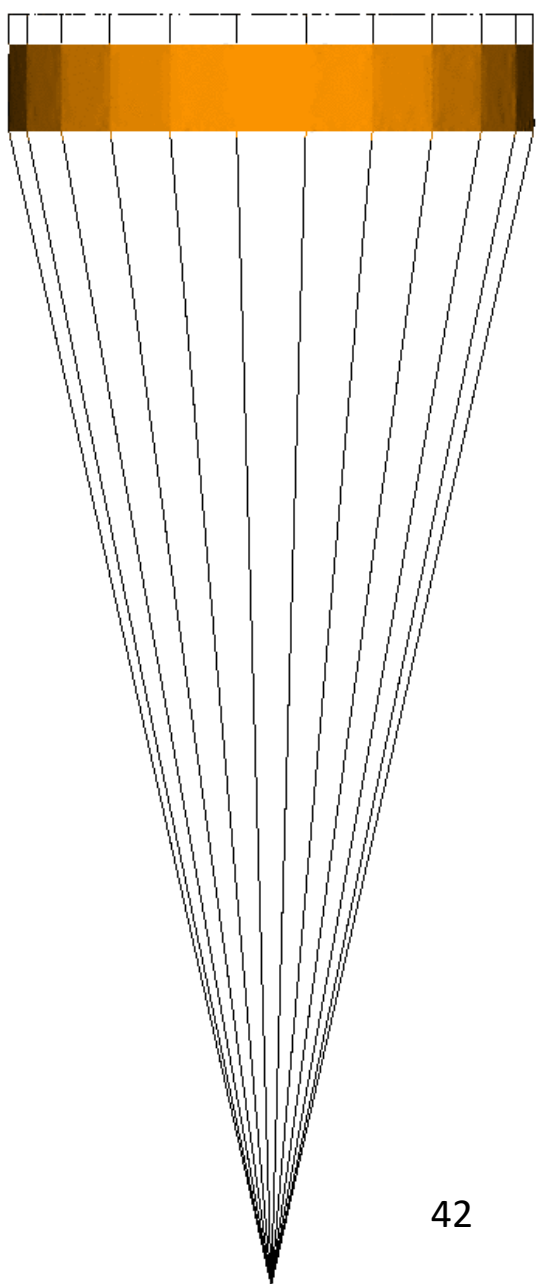




\section{Case 2: Leading Viking-type Capsule}

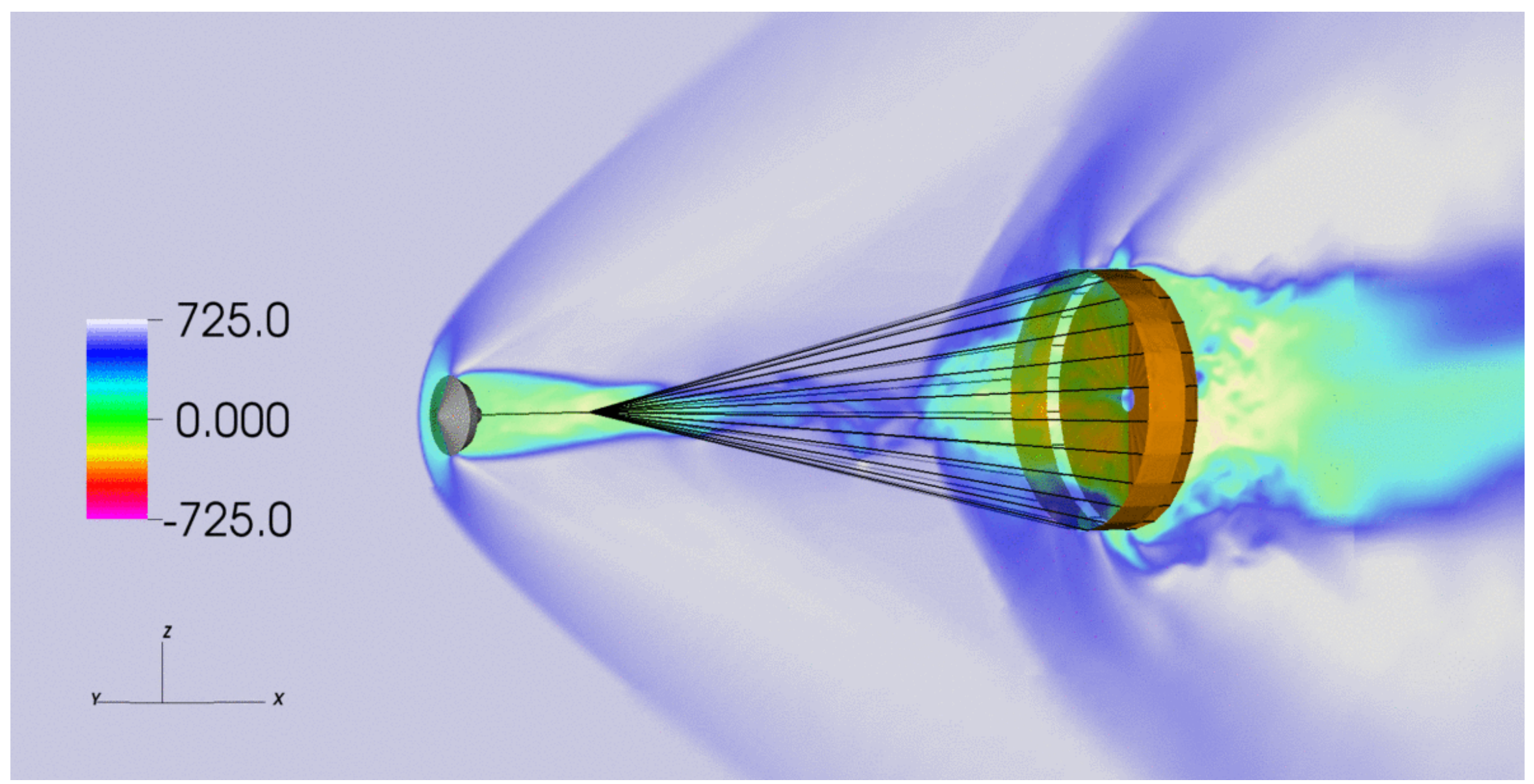

\section{Streamwise velocity}


$\square$ Motivation/Introduction

o Mars, EDL system qualification, Simulation Capabilities

$\square$ FSI Method

○ Governing equations

- Immersed Boundary Method for the Compressible Navier-Stokes Equations (CFD)

○ Geometrically Nonlinear Computational Structural Dynamics Solver (CSD)

○ Coupling procedure

$\square$ Extended Validation for Fluid-Structure Interaction Problems

$\square$ Methods for Large-scale, Parallel CFD-CSD Coupling

o Disparate domain decomposition

$\square$ Supersonic Parachute Inflation

\section{$\square$ Summary and Outlook}




\section{Summary and Outlook}

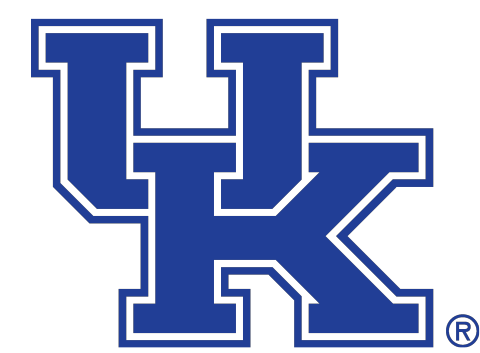

\section{$\square$ Summary:}

○ A validated method for FSI problems involving the large deformations of thin structures was extended to large, parallel simulations in supersonic flows

$\circ$ The details of the weak, parallel coupling algorithm and the treatment of dealing with the disparate partitions in the CFD and CSD solvers were discussed

○ The FSI method was then applied to two more large deformation FSI validation test cases to add onto the validation cases presented at SciTech 2019

o The FSI method was finally applied to the simulation of parachute inflation in the upper Martian atmosphere 


\section{Summary and Outlook}

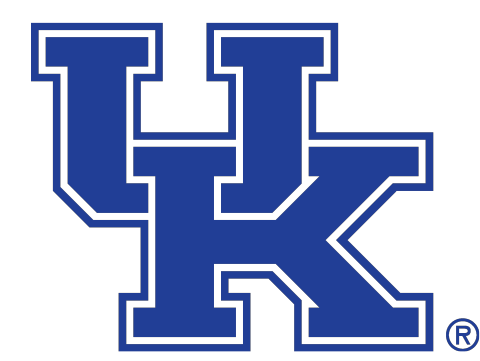

\section{$\square$ Outlook:}

o Treatment of the cable dynamics via damping, line drag

o Apply porous material boundary conditions on the canopy

O Implement more efficient contact algorithms for robustness

- Develop communication rings in the partitioned CFD-CSD solution procedure

○ Reduce overhead and general optimization, load balancing 


\section{Questions?}

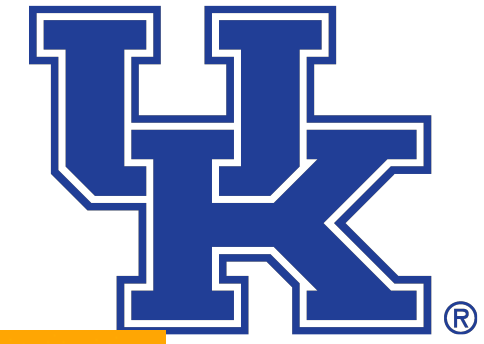

800.0

400.0

0.000 